NBER WORKING PAPER SERIES

\title{
UNEMPLOYMENT INSURANCE AND RESERVATION WAGES: EVIDENCE FROM ADMINISTRATIVE DATA
}

\author{
Thomas Le Barbanchon \\ Roland Rathelot \\ Alexandra Roulet \\ Working Paper 23406 \\ http://www.nber.org/papers/w23406 \\ NATIONAL BUREAU OF ECONOMIC RESEARCH \\ 1050 Massachusetts Avenue \\ Cambridge, MA 02138 \\ May 2017
}

For very helpful comments, we thank Jerome Adda, Philippe Aghion, Patrick Arni, Gary Chamberlain, Raj Chetty, David Cutler, Simon Jaeger, Xavier Jaravel, Lawrence Katz, Camille Landais, Rocco Macchiavello, Andreas Mueller, Nicola Pavoni, Barbara Petrongolo, Arne Uhlendorff, and seminar participants at Bocconi, CBS, CEPR/IZA ALES 2016, CREST, ECB/ CEPR labor workshop 2016, Harvard Labor Lunch, HKS, FBK-IRVAPP, INSEAD, JRC, PSE and TSE. We also thank the organizers of the TransAtlantic Public Economics Seminars on Social Insurance (TAPES 2016): Roger Gordon, Andreas Peichl and Jim Poterba. We are grateful to Pole Emploi, and in particular Anita Bonnet, for letting us access their data. The views expressed herein are those of the authors and do not necessarily reflect those of Pole Emploi. We gratefully acknowledge financial support from la Chaire de Securisation des Parcours Professionnels. Thomas Le Barbanchon is an IGIER and CEPR affiliate. All remaining errors are our own. The views expressed herein are those of the authors and do not necessarily reflect the views of the National Bureau of Economic Research.

NBER working papers are circulated for discussion and comment purposes. They have not been peer-reviewed or been subject to the review by the NBER Board of Directors that accompanies official NBER publications.

(C) 2017 by Thomas Le Barbanchon, Roland Rathelot, and Alexandra Roulet. All rights reserved. Short sections of text, not to exceed two paragraphs, may be quoted without explicit permission provided that full credit, including $(\odot$ notice, is given to the source. 
Unemployment Insurance and Reservation Wages: Evidence from Administrative Data

Thomas Le Barbanchon, Roland Rathelot, and Alexandra Roulet

NBER Working Paper No. 23406

May 2017

JEL No. J64,J65

\begin{abstract}
$\underline{\text { ABSTRACT }}$
Although the reservation wage plays a central role in job search models, empirical evidence on the determinants of reservation wages, including key policy variables such as unemployment insurance (UI), is scarce. In France, unemployed people must declare their reservation wage to the Public Employment Service when they register to claim UI benefits. We take advantage of these rich French administrative data and of a reform of UI rules to estimate the effect of the potential benefit duration (PBD) on reservation wages and on other dimensions of job selectivity, using a difference-in-difference strategy. We cannot reject that the elasticity of the reservation wage with respect to PBD is zero. Our results are precise and we can rule out elasticities larger than 0.006. Furthermore, we do not find any significant effects of PBD on the desired number of hours, duration of labor contract and commuting time/distance. The estimated elasticity of actual benefit duration with respect to PBD of 0.3 is in line with the consensus in the literature. Exploiting a regression discontinuity design as an alternative identification strategy, we find similar results.

Thomas Le Barbanchon

Bocconi University

Via Roentgen 1

Milano 20136

Italy

lebarbanchon@unibocconi.it

Roland Rathelot

University of Warwick

Department of Economics

Coventry CV4 7AL

UK

R.Rathelot@warwick.ac.uk

Alexandra Roulet

Harvard University and Insead

alexandra.roulet@gmail.com
\end{abstract}




\section{Introduction}

In standard job search models, unemployed workers receive job offers that they accept if the value of the offered job is higher than the value of unemployment (McCall, 1970). Their search strategy can be summarized by one key concept, the reservation wage, which is the lowest wage of an acceptable job offer. Job search models predict that more generous unemployment insurance (UI) increases the value of unemployment, and thus also increases reservation wages. This selectivity channel pushes up accepted wages. However, unemployment insurance also lengthens unemployment and, as job prospects decrease with unemployment duration, this negative-duration-dependence channel drives down accepted wages. Which channel dominates is a priori ambiguous and may depend on the context. A recent strand of the empirical literature documents modest - either positive or negative - UI effects on accepted wages (Card et al., 2007; Schmieder et al., 2012b, 2016; Le Barbanchon, 2016; Nekoei and Weber, 2017). ${ }^{1}$ However, the existing literature has no precise estimate of the UI effect on reservation wages only, which corresponds to the selectivity channel. Our paper contributes to filling this gap.

We take advantage of unique administrative data on reservation wages and of a quasiexperimental research design. In France, when newly unemployed job seekers register at the public employment service, they have to declare their reservation wage and other information on the job they are looking for, such as commuting time/distance, desired number of hours and type of labor contract (temporary vs. long-term). Our main identification strategy relies on a reform that altered the Potential Benefit Duration (PBD) for some claimants groups while leaving it unchanged for some others, depending on their previous work tenure. Using this natural experiment, we compute difference-in-difference estimates of the elasticity of reservation wages with respect to PBD. Our results point to the lack of responsiveness of reservation wages and other dimensions of job selectivity to the potential duration of benefits. We obtain very similar results using an alternative identification strategy, based on the discontinuity of the PBD schedule with age.

While the previous literature on reservation wages is based on survey data (Feldstein and Poterba, 1984; Koenig et al., 2014; Krueger and Mueller, 2016), we use administrative data on reservation wages. Our data have thus several strengths: large sample size, no missing values due to non-response and precise measures of UI-related policy variables and past labor outcomes, such as past tenure or past wages. On top of these strengths, the data also enable us to follow workers over multiple claims, so that we observe repeated measures of reservations wages for a given worker. As a sanity check, we verify that claimants

\footnotetext{
${ }^{1}$ See Schmieder and von Wachter (2016) for a recent literature review on the impact of unemployment insurance on non-employment duration.
} 
stating higher reservation wages draw on UI benefits for a longer time period, holding constant the claimants' and the claims' characteristics, and controlling for unobserved timeinvariant heterogeneity of claimants (fixed effects models). This first result confirms that the reservation wage stated by claimants to the UI agency is meaningful.

Our main identification strategy relies on a UI reform, which occurred in 2009. The reform was not triggered by the Great Recession. Its main objective was to simplify the rules according to which the potential duration of benefits are computed. In France, PBD is mainly determined by the claimant's previous work duration. Before the 2009 reform, PBD was a step function of past tenure. The 2009 reform simplified the rule and made it linear, so that claimants are now entitled to as many days of benefits as days of work in the previous two years. Some tenure groups benefited from the reform while others lost. Some tenure groups were unaffected and can be used as control groups in a difference-indifference setting.

Whatever the statistical specification we use, we cannot reject that the elasticity of reservation wages with respect to PBD is zero at the 5\% level. Our results are precise and, in our favorite specification, rule out elasticities greater than 0.006 . The elasticity of the actual duration of benefits with respect to PBD, estimated at 0.3 , is in line with most results of the literature. We also find that more generous benefits slow down job finding even at the beginning of the spell when claimants declare their reservation wages.

Looking at other dimensions of job selectivity, we do not find any significant effect of PBD on the maximum commuting time/distance that job seekers are willing to accept. Nor do we find any effects of PBD on the number of hours or on the type of contract job seekers are looking for. The absence of responsiveness in all dimensions of job selectivity is a strong result. While the non-responsiveness of reservation wages could have been explained by strong wage rigidity and low mobility across jobs, the fact that the willingness to find open-ended contracts and to ensure job security does not change with PBD suggests that rigid labor markets are unlikely to be the only explanation to our results.

While the elasticity of reservation wages is zero on average, we find that it amounts to a significant 0.01 for job seekers with the lowest past tenure. These job seekers are entitled to short PBD and the date when their benefits could elapse is close to their registration date when they declare their reservation wages. Consistently, we also find that the elasticity of actual benefit duration is higher for these short tenure claimants. We do not find any significant heterogeneity of the PBD elasticity of reservation wages across gender or past wage groups.

We are able to check the robustness of our main results using another identification strategy, a Regression Discontinuity Design (RDD). When unemployed job seekers are over 50 years 
old at the separation date from their previous employer, they benefit from more generous PBDs, which are on average $30 \%$ longer. We find some manipulation of the separation date around the 50-year-old cutoff. Consequently, we adopt a "Donut" RDD strategy, which excludes observations in a window around the cutoff of the running variable. As with our main difference-in-difference strategy, we cannot reject that the PBD elasticity of reservation wages is equal to zero, while the elasticity of actual benefit duration is around 0.2. Claimants in the RDD strategy are different from those of the difference-in-difference, in particular they are more attached to the labor force and older; yet results are very similar.

Lastly, we discuss the theoretical relation between the elasticities of unemployment duration and the reservation wage with respect to PBD. In partial equilibrium, we can decompose the elasticity of unemployment duration into two components: one due to the elasticity of the reservation wage (scaled by the slope of the wage offer distribution taken at the level of the reservation wage) and the other one due to the elasticity of the job offer arrival rate (or search effort). Taking the upper bound of the $95 \%$ confidence interval of the estimate of the reservation wage elasticity, we find that the reservation wage margin accounts, at most, for $6 \%$ of the elasticity of unemployment duration, the rest being attributed to the elasticity of search effort.

Our paper is, to the best of our knowledge, the first one to obtain precise quasi-experimental estimates of the effect of more generous UI on self-reported reservation wages and other dimensions of job selectivity. Most previous contributions could not rely on credible exogenous variations in UI generosity and found mixed results. Feldstein and Poterba (1984) finds a large elasticity of reservation wages to benefit levels, while Krueger and Mueller (2016) cannot reject that this elasticity is equal to zero. ${ }^{2}$

Our findings on reservation wage responsiveness shed lights on the current debate on the effect of UI on accepted wages. Our results show that changes in PBD have no significant effect on job selectivity at the beginning of the job-search spell for the average job seeker. The absence of selectivity effect is in line with the conclusion of Schmieder et al. (2016) that reservation wages are not binding in Germany. When we focus on job seekers with short potential benefit duration, who are more comparable to claimants in the Austrian sample of Nekoei and Weber (2017), we find an estimate of the elasticity of reservation wages around .01, which has a similar magnitude as the estimate found by Nekoei and Weber (2017) on the elasticity of accepted wages with respect to PBD (.016).

Section 2 describes the 2009 UI reform and the data. Section 3 explains our DiD strategy and provides evidence in favor of the identification assumptions. Section 4 presents the

\footnotetext{
${ }^{2}$ One recent exception is Lichter (2016) who uses a quasi-experimental setting to analyze the effect of PBD on job search effort, but also on reservation wages. His results on reservation wages are consistent with ours, although less precise because of the small sample size of his survey data.
} 
main estimates of the effects of PBD on job selectivity and the analysis of their heterogeneity. Section 5 deals with our alternative RDD strategy. Section 6 discusses the relationship between the elasticities of reservation wages and unemployment duration with respect to PBD. Section 7 concludes.

\section{Research design and data}

\subsection{Research design}

Our identification strategy relies on a change in UI rules that occurred at the beginning of 2009. The 2009 reform was not triggered by the Great Recession. In France, UI rules are renegotiated by unions and employers' organizations every three years. The renegotiation was thus expected but the nature of the change was not anticipated. The objective of the 2009 change was to simplify the computation of Potential Benefit Duration (PBD), i.e. the number of days of benefits workers are entitled to when they become unemployed. Both before and after the change, PBD depends on the number of days worked in the previous years but in a different way. For workers aged less than 50, before the reform, PBD could take three values: i) 213 days if the unemployed had worked between 182 and 365 days (excl.) in the previous 26 months, ii) 365 days if she had worked between 365 and 487 days (excl.); and iii) 700 days if she had worked 487 days or more. After the reform, the unemployed are entitled to as many days of benefits as they worked in the reference period, with a cap at 730 days. In the current section, we restrict ourselves to workers less than 50 years old. The UI rules are more generous for workers of more than 50 years old, a group on which we focus in our alternative identification strategy in Section 5.

Figure 1 shows this shift from a step function to a linear function. Some tenure groups benefited from the change, whereas others lost from it, and within winners and losers, some tenures were associated with larger changes than others. The new UI rule applies to anyone whose contract terminated after March 31st 2009. ${ }^{3}$

\subsection{Sample selection}

From the administrative records of the Public Employment Service (PES), we select the inflow of job seekers registering for a new UI claim from 2006 to 2012. ${ }^{4}$ We focus on claimants of the regular UI rules, excluding senior workers over 50 years old, workers from

\footnotetext{
${ }^{3}$ People whose contract terminated before and who are still unemployed on March 31st 2009 stay entitled to the old rule.

${ }^{4} \mathrm{New}$ claims correspond both to first claims ever and to situations when a worker registers again and has no benefits left from her previous claim.
} 
Figure 1: Schedules of PBD, before and after the 2009 reform

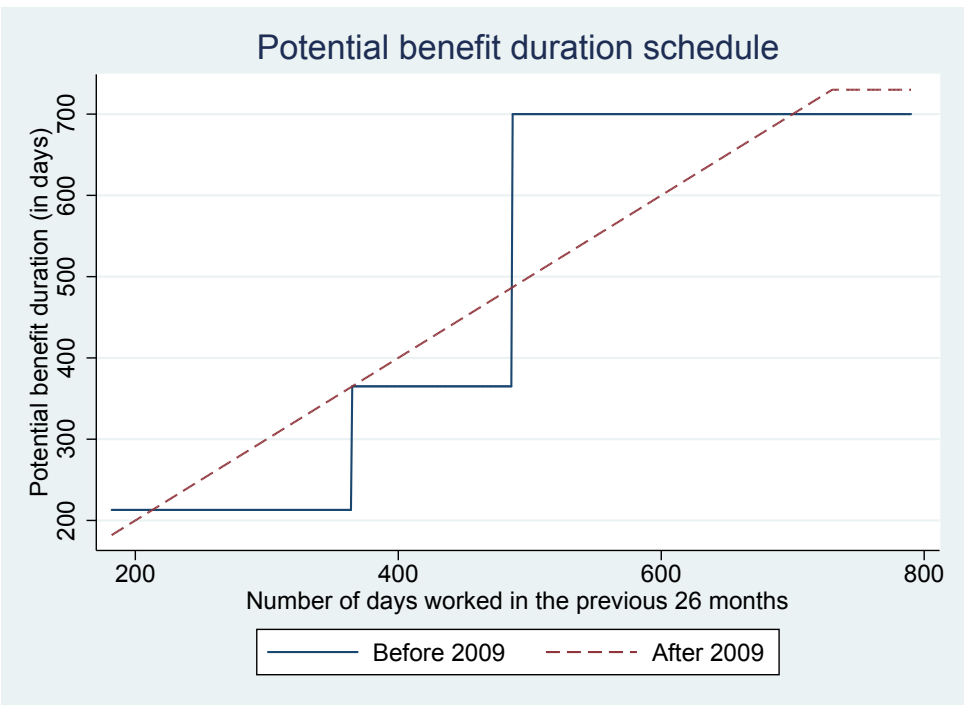

temporary help agencies -interimaires- and workers in the culture and arts industries intermittents $d u$ spectacle. We restrict the sample to claimants that were previously employed full-time. This resolves any ambiguity about the reservation wage question (see below). Finally, we exclude observations with extreme past wages or reservation wages. ${ }^{5}$

We further select unemployed people whose pre-unemployment contract terminated between April 1st 2006 and March 31st 2012, 3 years before and after the 2009 reform. Although we show the main results on the full sample as well, the analysis (until Section 5) focuses on claimants with multiple claims, more precisely with exactly two claims (there are very few individuals with 3 claims or more so we drop them ${ }^{6}$ ). Focusing on claimants with multiple spells enables us to control for time-invariant unobserved heterogeneity, for instance, in productivity, which is important to make sense of the link between reservation wages and unemployment duration as we show in section 2.3. Controlling for time-invariant heterogeneity is also a plus when implementing our difference-in-difference strategy (see section 3). We also believe that job seekers with multiple spells have a better knowledge of the UI system and are thus more likely to react to changes in the PBD schedule. Our final sample has around 180,000 claims, while the full sample of both onespell and multiple-spells claimants has around 2,000,000 claims. Summary statistics can be found in Appendix Table A1.

\footnotetext{
${ }^{5}$ Observations with reservation wages or past wages below the minimum wages are excluded. We also exclude observations whose past wage is over 3,400 euros, or whose reservation wage is over 3,200 euros (95\% percentile). We trim observations with a ratio of the reservation wage over the previous wage that is below 0.4 or above 3 (the first and last percentile).

${ }^{6}$ They account for less than $1 \%$ of all claims
} 


\subsection{Reservation wage data}

When registering as unemployed in France, people are asked the type of job they are looking for and their reservation wage for this job. Figure 2 is a screenshot of the online registration form. The question is stated in these terms: "What minimum gross wage do you ask for?". People indicate an amount and choose the unit in which they are reporting their reservation wage: hourly, monthly or annual. Before answering the reservation wage question, they are asked what occupations they are looking for. These occupations may be different from their previous job and they probably provide some kind of anchor for the reservation wage question. Job seekers cannot move on to the next page without having reported their reservation wage.

Figure 2: Screenshot of the section dedicated to reservation wage on the PES website at registration

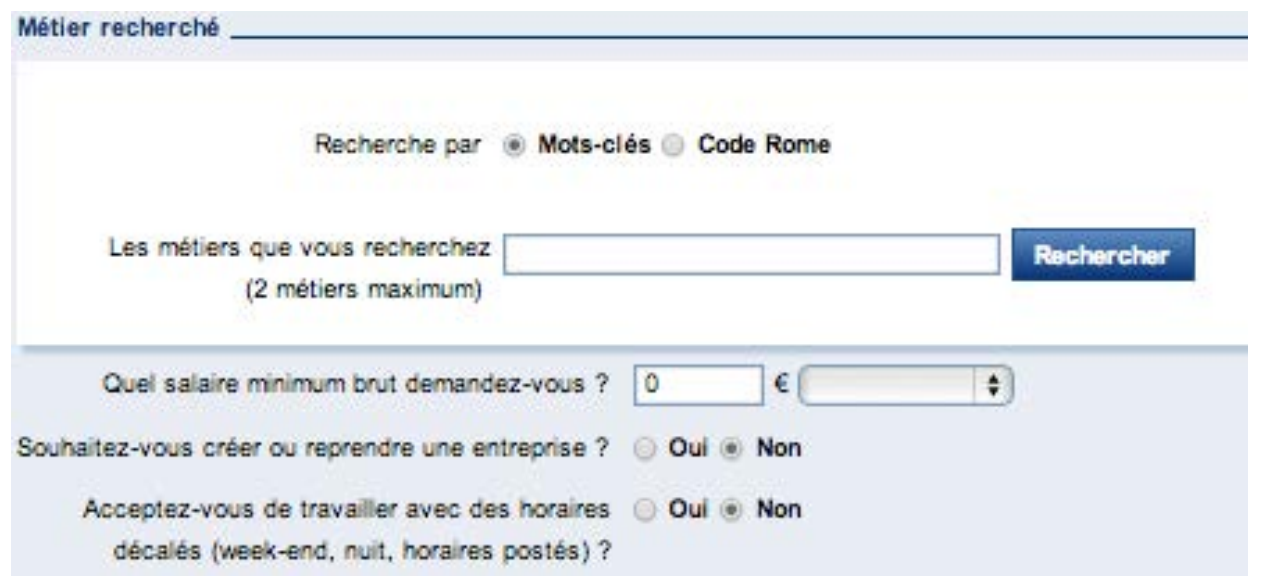

After the reservations wage, questions about desired hours, type of labor contracts (longterm vs temporary contrats), commuting times/distances are asked in order to help the PES caseworkers choose the type of vacancies they will send to each job seeker. ${ }^{7}$ If browsing through vacancies is costly for job seekers, basic theory suggests that the best response of job seekers is to reveal their true reservation wage to the PES. ${ }^{8}$ We are also confident that the monitoring/sanctioning role of the PES does not lead job seekers to lie about their reservation wages. Indeed, when controlling the search effort of job seekers, the legal rule

\footnotetext{
${ }^{7}$ The fact that these variables are used for this purpose is confirmed here: http://www.pole-emploi.fr/ candidat/le-projet-personnalise-d-acces-a-l-emploi-@/article.jspz?id=60640.

${ }^{8}$ In case of incomplete information, this conclusion may not hold. Assume for instance that job seekers do not know for certain the distribution of wage offers when they answer the question. In this case, they may be tempted to declare a lower reservation wage than their true one, to learn about the distribution. Interestingly though, shorter PBD would then lead job seekers to declare even lower reservation wages, as they need to learn more quickly. This would amplify the impact of PBD on the observed reservation wage, which is at odds with our results.
} 
requires caseworkers to compare the posted wages of vacancies to which job seekers apply to their past wage - and not to their reservation wages. ${ }^{9}$ Anecdotal evidence also suggest that sanctions for failing to comply to job-search requirements are never implemented.

We focus on job seekers previously working full-time because the reservation wage question is not explicit about whether it relates to full-time or part-time jobs. Almost all job seekers in our sample look for a full-time job (see Section 2.4) and the reservation wage data can be interpreted as being in relation to a full-time job.

Figure 3 shows the distribution of the monthly reservation wage. ${ }^{10}$ The upper panel displays the reservation wage (in nominal terms). In the intermediate panel, the reservation wage is divided by the minimum wage at the time of registration. The lower panel displays the reservation wage divided by the pre-unemployment wage. Figure 3 shows that 35\% of workers report the minimum wage as their reservation wage. The minimum wage is high in France ${ }^{11}$ and applies to a large share of the workforce: $40 \%$ of the unemployment spells of our sample are associated with a previous wage that is inferior or equal to 1.2 times the minimum wage. The upper panel of Figure 3 also shows that individuals tend to round their stated reservations wages to hundreds of euros. We discuss the consequences of rounding on our identification in Appendix A. We show that the non-classical measurement error in our main outcome variable induced by rounding is unlikely to bias our main estimates, as the exogenous variation in PBD used in our context is independent of the measurement error.

Dividing the reservation wage by the past wage in the lower panel is a first attempt to control for individual heterogeneity. It captures whether people are being more or less picky, for instance whether they are willing to accept a wage cut. $70 \%$ of job seekers would accept a job that pays less than their previous job. The median of the reservation wage ratio is 0.93 . The distribution of the reservation wage ratio in our data, is close to the one obtained by Feldstein and Poterba (1984) or Krueger and Mueller (2016).

One potential concern to address is the extent to which, conditional on the previous wage, the reservation wage conveys some additional information. It could be for instance that the reservation wage is anchored on the previous wage with some noise. We show that the reservation wage carries information. First, the reservation wage is meaningfully correlated with workers' characteristics. Second, we show that the reservation wage helps to predict actual benefit duration, even conditional on past wages. In the remainder of the text, we also use the term "unemployment duration" for actual benefit duration.

\footnotetext{
${ }^{9}$ See https://www.legifrance.gouv.fr/eli/loi/2008/8/1/ECEX0812043L/jo/texte for more details.

${ }^{10}$ We convert in monthly terms wages declared in hours or in annual terms, using the legal number of working hours for full-time employees.

${ }^{11}$ For instance, in 2012, the gross monthly minimum wage was 1400 euros.
} 
Figure 3: Distribution of reservation wages

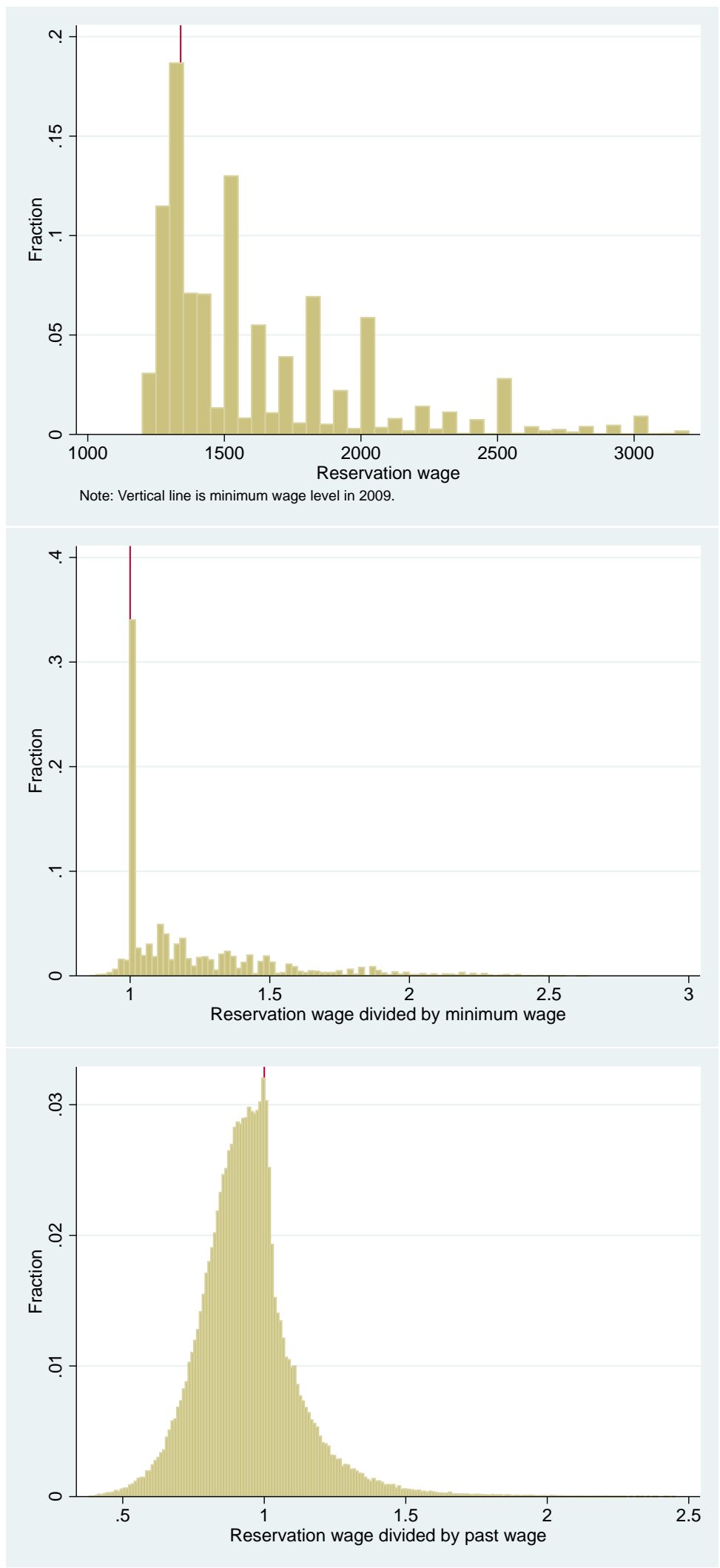


First, Table 1 shows how workers' characteristics are correlated with the reservation wage, controlling non-parametrically for the previous wage. ${ }^{12}$ Conditional on the previous wage, women tend to have a lower reservation wage. On the contrary, age, experience and education all lead to a higher reservation wage.

Table 1: Socio-demographic determinants of reservation wages

\begin{tabular}{lcc}
\hline & $\begin{array}{c}\text { Reservation } \\
\text { wage }\end{array}$ & $\begin{array}{c}\text { Reservation wage } \\
\text { over past wage }\end{array}$ \\
\hline Dummies for 20 equal & $\mathrm{x}$ & $\mathrm{x}$ \\
sized bins of past wage & $-44.52^{* * *}$ & $-0.0289^{* * *}$ \\
Female & $(1.650)$ & $(0.000904)$ \\
Married * Female & $-20.86^{* * *}$ & $-0.0129^{* * *}$ \\
Married * Male & $(2.000)$ & $(0.00107)$ \\
Age & $39.15^{* * *}$ & $0.0220^{* * *}$ \\
Experience & $(2.043)$ & $(0.00111)$ \\
Education & $2.510^{* * *}$ & $0.00148^{* * *}$ \\
& $(0.101)$ & $(5.53 \mathrm{e}-05)$ \\
\hline Obs. & $8.131^{* * *}$ & $0.00456^{* * * *}$ \\
R-squared & $(0.171)$ & $(9.16 \mathrm{e}-05)$ \\
\hline
\end{tabular}

Source: FNA-FH (Pole emploi).

Note: Estimates from an OLS regression. Robust standard errors in parentheses. ${ }^{* * *} \mathrm{p}<0.01,{ }^{* *} \mathrm{p}<0.05,{ }^{*} \mathrm{p}<0.1$.

Second, we show that higher reservation wages predict longer unemployment duration. One concern is that the empirical relationship between the reservation wage and unemployment duration, controlling for observables, is likely to reflect both the causal effect of the reservation wage on unemployment duration and the influence on the reservation wages of unobservables that are also correlated with unemployment duration. The workers who are more productive are likely to have better prospects and thus higher reservation wages. They are also more likely to stay unemployed for shorter periods. The unobserved heterogeneity in productivity is likely to create a negative relationship between reservation wage and unemployment duration, holding observables constant. We test whether this unobserved heterogeneity matters by estimating the following equation with and without individual fixed effects:

$$
\log \operatorname{Dur}_{i, n}=\text { Indiv.F.E. }{ }_{\cdot i}+\delta \log r e s W_{i, n}+\beta X_{i, n}+\epsilon_{i, n}
$$

\footnotetext{
${ }^{12}$ We split the sample in 20 equal-sized bins in terms of previous wage and use dummies for these bins
} 
where $D u r_{i, n}$ is the duration of the $n$-th claim of individual $i$; res $W_{i, n}$ is the reservation wage declared by individual $i$ at the beginning of her $n$-th claim; $X_{i, n}$ are a set of covariates including the log of PBD, time fixed effects (quarterly date of registration), 50 past wage bins and age (see footnote of Table 2 for the exhaustive list). First, the OLS coefficient without individual fixed effects (Column (1) in Table 2) is negative and equal to -0.16 . This suggests that the unobservable productivity component of reservation wages dominates the correlation. Then we estimate the fixed effects regression and find a positive significant coefficient of 0.28 (Column (2) in Table 2). Once we control for unobserved (time invariant) heterogeneity using the individual fixed effects, the relationship between unemployment duration and reservation wages only reflects the differences between claims in the work vs. non-work valuation. The comparison between Column (1) and Column (2) of Table 2 shows the importance of controlling for unobserved (time-invariant) heterogeneity. This justifies our choice of selecting a sample of job seekers with multiple claims, which enables fixed effects estimation. While this selection is admittedly important - job seekers with multiple spells are probably less productive than those with one spell only -, the OLS coefficient of Column (1) in Table 2 does not change much when it is estimated on the whole sample in Column (3) (-0.21 vs. -0.16).

Table 2: Unemployment duration and reservation wage

\begin{tabular}{lccc}
\hline & \multicolumn{3}{c}{ Log unemployment duration } \\
\cline { 2 - 4 } & OLS & FE-OLS & OLS \\
& $(1)$ & $(2)$ & $(3)$ \\
\hline Log reservation wage & $-0.155^{* * *}$ & $0.277^{* * *}$ & $-0.210^{* * *}$ \\
& $(0.0149)$ & $(0.0337)$ & $(.0048)$ \\
\hline Sample & multiple-spell & multiple-spell & full sample \\
Obs. & 180,637 & 180,637 & $1,957,794$ \\
R-squared & 0.063 & 0.091 & 0.066 \\
\hline
\end{tabular}

Source: FNA-FH (Pole emploi).

Note: Estimates from an OLS regression. Are included in the specification time fixed-effects as well as individual controls: log of PBD, 50 past wage bins, gender, gender interacted with family status dummies (married, divorced, widow, having kids), foreign born, age and age square, experience and experience square, education, reason of separation from previous job, quarterly inflows of new job seekers and of vacancies in the commuting zone (both in logs). Robust standard errors in parentheses. ${ }^{* *} \mathrm{p}<0.01,{ }^{* *} \mathrm{p}<0.05,{ }^{*} \mathrm{p}<0.1$.

Figure 4 shows the distribution of the difference between the reservation wages declared by the same individual at the beginning of her first and second spell over our period of analysis. As the figure shows, although $35 \%$ of job seekers declare the same real reservation wage for their two unemployment spells, there is still some variability that we relate to exogenous variations in PBD in Sections 3 and 4. 
Figure 4: Within individual variation in the reservation wage
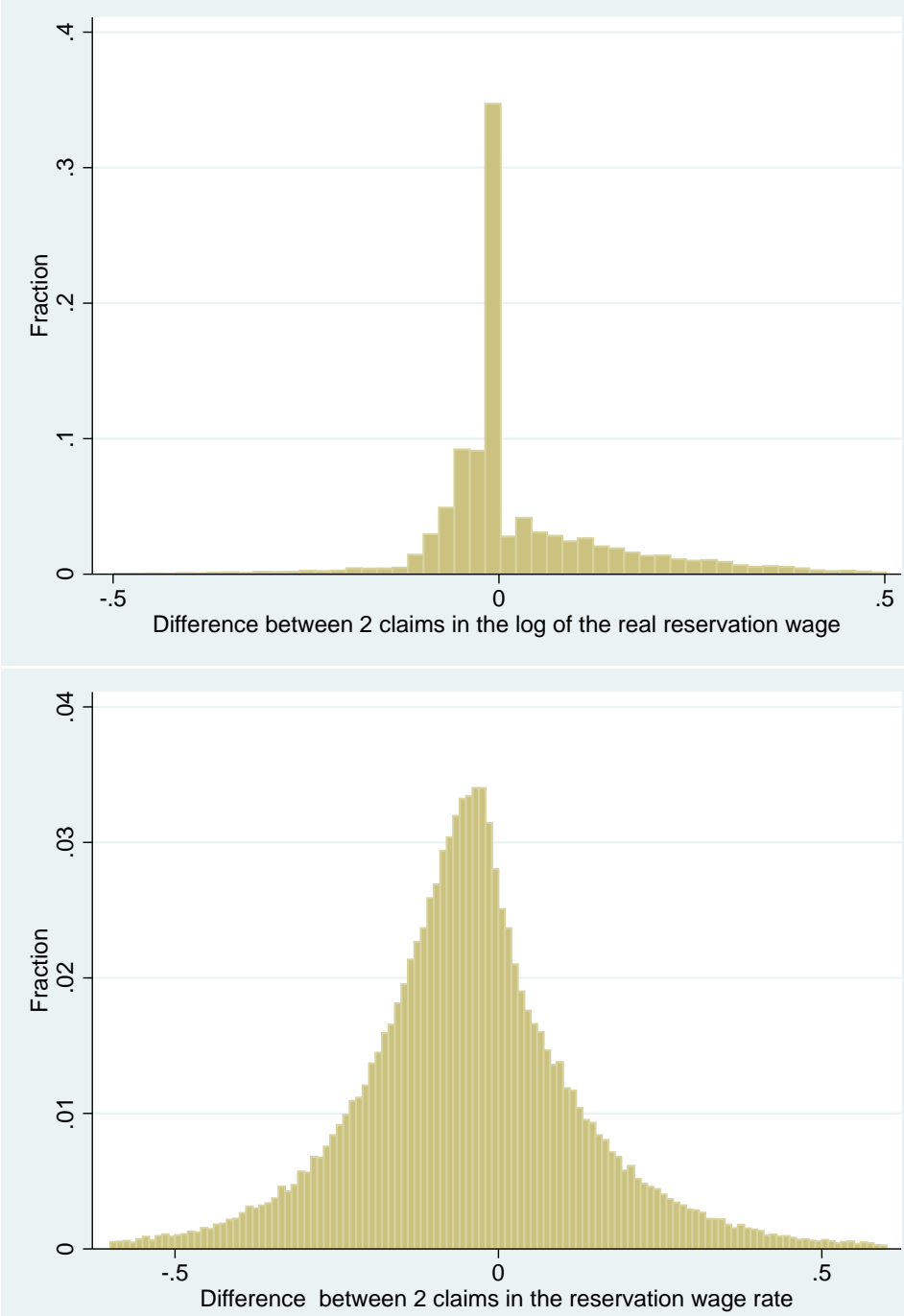

Source: FNA-FH (Pole emploi). Note: Upper panel: we divide the reservation wage by the minimum wage prevailing at the time of unemployment registration. Lower panel: the reservation wage ratio is the ratio of the reservation wage over the previous wage. 


\subsection{Data on other dimensions of job selectivity}

During the registration process and after stating their reservation wage, job seekers are also asked about other characteristics of the job they are looking for. They are asked the type of contract and the type of hours they would like. In France, there is a strong duality in the labor market between jobs with open-ended contracts and jobs with temporary contracts. Open-ended contracts ensure that workers benefit from a high level of employment protection: we call them long-term contracts. Table 3 shows that almost $90 \%$ of job seekers declare that they are looking for such contracts. This is in sharp contrast with the share of job seekers separating from a long-term contract, which amounts to $35 \%$. In contrast to the wage dimension along which the unemployed are willing to accept a cut, job seekers are looking for jobs with more job security than their previous jobs. Table 3 also shows that $97 \%$ of job seekers are looking for a full-time job.

Table 3 also reveals the extent to which job seekers are mobile. On average, job seekers declare that they would accept a job that is in a $32 \mathrm{~km}$ radius around their home. ${ }^{13}$ For those who give a commuting time, on average they would accept a maximum of 44 minutes of commute. $2 \%$ of job seekers declare that they would accept a job anywhere in France. When estimating the effect of UI on mobility, we will abstract from this last category.

As we do not observe the occupation of job seekers in their previous jobs, we cannot study how mobile job seekers are in the occupational dimension.

Table 3: Reservation Strategy - all dimensions

\begin{tabular}{lccc}
\hline \multicolumn{1}{c}{ Variable } & Mean & Std. Dev. & N \\
\hline Past Wage (gross monthly, in euros) & 1721.6 & 388.4 & 180,670 \\
Unemployment Benefits (gross monthly, in euros) & 1006.9 & 226.5 & 180,670 \\
Reservation Wage (gross monthly, in euros) & 1599.9 & 382.1 & 180,670 \\
Past Contract is long-term (a) & 0.353 & 0.478 & 166,486 \\
Looking for a long-term contract & 0.895 & 0.307 & 180,670 \\
Past job is full-time (b) & 1 &. & 180,670 \\
Looking for a full-time job & 0.971 & 0.167 & 180,670 \\
Maximum commute time accepted (in minutes) (c) & 44.441 & 19.974 & 53,880 \\
Maximum commute distance accepted (in kilometers) (c) & 31.538 & 24.4 & 109,620 \\
No geographical constraint & 0.02 & 0.138 & 180,670 \\
\hline
\end{tabular}

Source: FNA-FH (Pole emploi).

Note: (a) The data is missing for $7.9 \%$ of the ample; (b) We selected our sample among workers with full-time jobs before unemployment. ; (c) The question on commuting time/distance is not mandatory, so that the corresponding variable is missing for $7 \%$ of our sample.

\footnotetext{
${ }^{13}$ Unfortunately, our data do not comprise the commuting distance/time to the previous job. A recent survey conducted on a representative sample of the employed population reveals that the average 2-way commuting time is 50 minutes. http://dares.travail-emploi.gouv.fr/IMG/pdf/2015-081.pdf
} 


\section{Empirical strategy: difference in differences}

Our preferred identification strategy relies on exogenous variations in the Potential Benefit Duration (PBD) triggered by the 2009 reform of the Unemployment Insurance (UI) rules. Whereas Figure 1 displayed the theoretical change in PBD, Figure 5 exhibits the variation in PBD as we observe it in the data. More precisely we plot the $\alpha_{j}$ coefficients from the following regression

$$
P B D_{i, n}=\sum_{j=6}^{26} \alpha_{j} D\left(\text { Tenure }_{i, n}=j\right) \times \text { After }_{i, n}+\sum_{j=6}^{26} \delta_{j} D\left(\text { Tenure }_{i, n}=j\right)+\text { Indiv.F.E. }+v_{i, n}
$$

where $i, n$ denotes the $\mathrm{n}$-th unemployment spell of individual i. Tenure $i_{i, n}$ is the number of months worked in the 26 months before the beginning of this spell. ${ }^{14}$ After $i, n$ is a dummy variable equal to 1 if the last job before the claim terminated after March 31st 2009.

Figure 5: Treatment: Potential Benefit Duration, in levels (days)

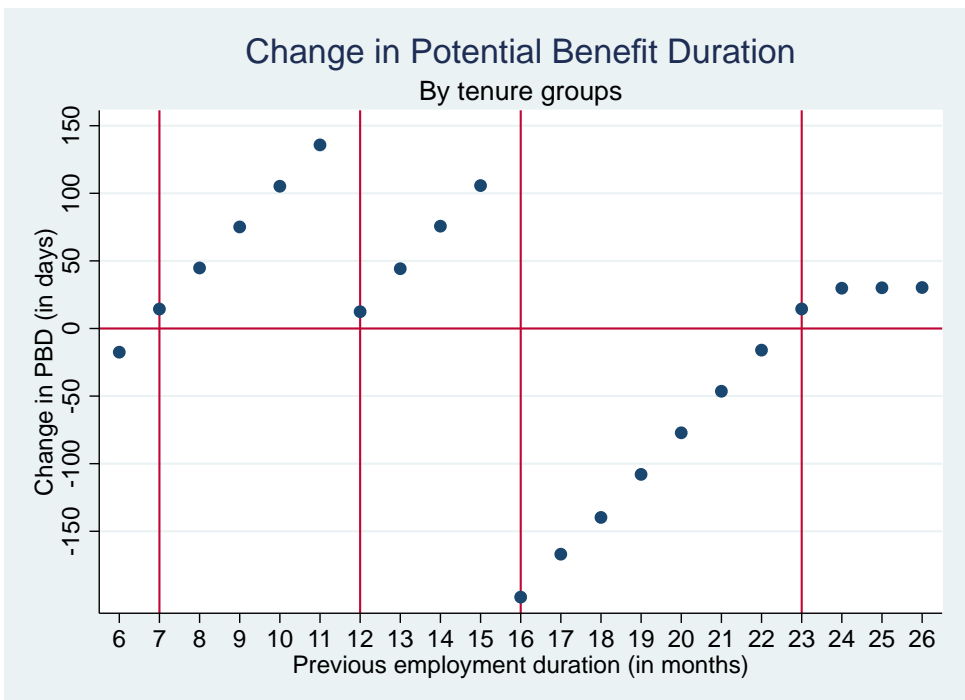

Figure 5 highlights that our identification strategy can be thought of as a difference-indifference analysis. For job seekers with past tenure equal to 7 months, 12 months and 23 months, PBD according to the 2009 rules is just 15 days over what it would have been under the 2006 rules. These tenure groups constitute our control groups. All other tenure groups experience larger changes in PBD. Several assumptions are needed to ensure that our design actually identifies the effect of PBD.

The main assumption is the common trends assumption. Figure 6 presents a graphical

\footnotetext{
${ }^{14}$ The past employment duration which is available in days in the data, is rounded down in number of months.
} 
check of the validity of this assumption. Because we have a continuous treatment, for the purpose of this test only, we constitute two equal-sized groups based on the size of the change triggered by the reform. The median change is a 30-day increase in PBD. We split the sample between tenure groups that are above and below the median. For these two groups, we plot in Figure 6 the evolution over time of the main outcomes of interest: the reservation wage and the actual duration of benefits. The red line with squares shows the evolution of these outcomes for workers whose tenure would make them lose from the reform or gain less than 30 days. The blue line with triangles shows the evolution for workers whose tenure would make them gain more than 30 days of PBD. Figure 6 shows roughly parallel trends before the reform, for both outcomes. These graphs also preview the results presented in the next section: the actual duration of benefits seems to be affected by the reform whereas this is not obvious for the reservation wage.

Figure 6: Common trends
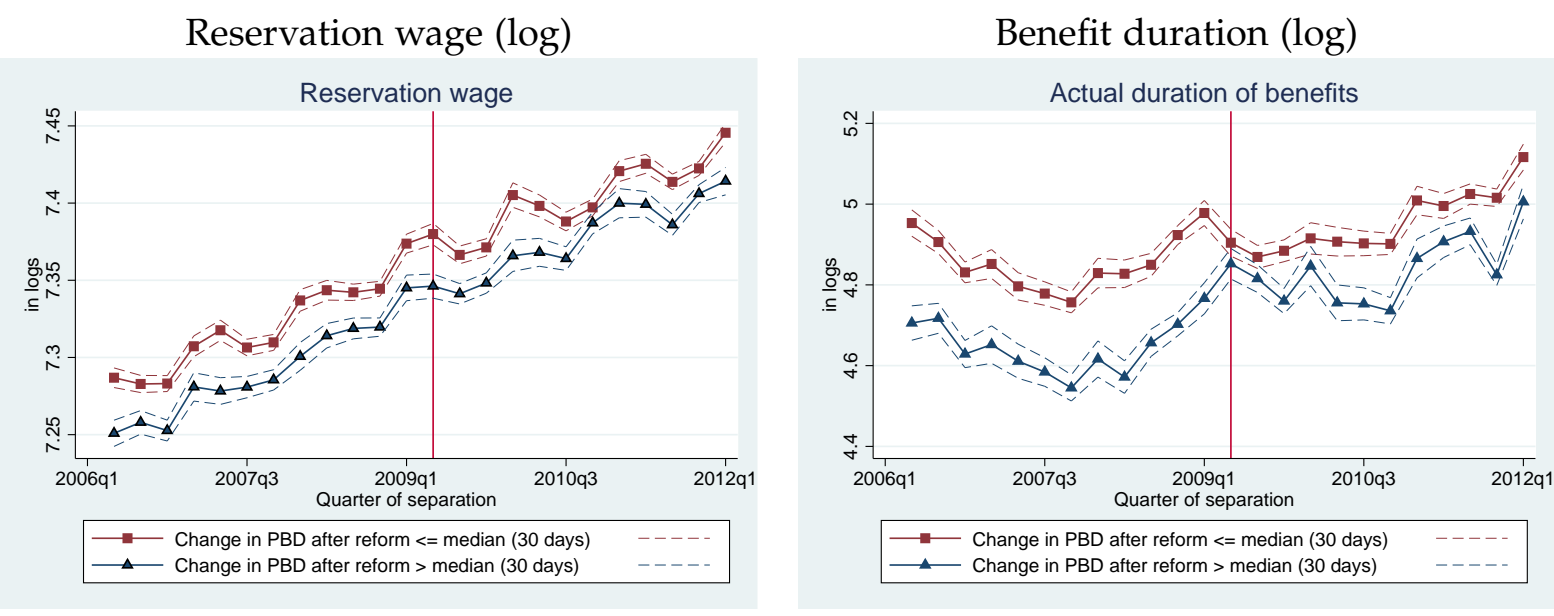

One may be concerned that the difference-in-difference groups are defined according to an endogenous variable: past tenure. We verify in Appendix Figure A3 that the tenure distribution is similar over time and does not seem to be affected by the 2009 reform. ${ }^{15}$ In Section 4, we also show results of placebo tests that further confirm our identification strategy.

Another concern is related to the differential selection of claimants after the Great Recession. For example, the 2008-2009 crisis may have triggered early separations of productive individuals, thus affecting differently the average productivity of tenure groups. Our focus on multiple spell individuals allows us to control for time-invariant unobserved hetero-

\footnotetext{
${ }^{15}$ Appendix Figure A4 shows a further test. We compute from the tenure distributions the average PBD according to both the 2006 and 2009 rules. We show that the evolution of the average PBD according to both rules is parallel over time.
} 
geneity, e.g. in productivity, and thus partly alleviates this concern.

Finally, the Stable Unit Treatment Value Assumption (SUTVA) states that each tenure group is not affected by the fact that workers in other tenure groups are treated differently. Lalive et al. (2015) show that UI affects equilibrium conditions on the labor market. Compared to other reforms that have been studied, the 2009 reform is less likely to violate the SUTVA as there are both winners and losers, so that the overall generosity of the system does not change much.

\section{Main results}

In this section, we present our main estimates of the effect of the Potential Benefit Duration (PBD) on the reservation wage, the actual benefit duration, and the other dimensions of job selectivity. Then, we present an analysis of the heterogeneity of the effects according to workers' characteristics.

\subsection{Reduced-form effect of the reform}

We first estimate the reduced form effect of the reform, tenure group by tenure group.

$$
\begin{aligned}
& \log Y_{i, n}=\sum_{j=6, \text { excl. } 7,12,23^{26}} \beta_{j} D\left(\text { Tenure }_{i, n}=j\right) \times \text { After }_{i, n}+\sum_{j=6, \text { excl. }_{1,12,23}}^{26} \delta_{j} D\left(\text { Tenure }_{i, n}=j\right) \\
& +X_{i, n} \gamma+\text { Year } \times \text { QuarterF.E. }+ \text { Indiv.F.E. } i+v_{i, n}
\end{aligned}
$$

$Y_{i, n}$ is either the reservation wage or the number of days of benefit receipt for the $\mathrm{n}$-th claim of individual i. $X_{i, n}$ are job seeker's observable characteristics. These include gender, age and experience, age square and experience square, number of years of schooling, marital status and number of children, a dummy for being foreign born, and dummies for 20 bins of the previous wage. ${ }^{16}$ We also include dummy variables for the year $\times$ quarter at which the previous job ended. We show the results with the individual controls and the year $\times$ quarter fixed effects but the patterns are similar without these individual controls (and replacing the time fixed effects by the time dummy for the reform After $_{i, n}$ ).

The main coefficients of interest in this regression are the $\beta_{j}$ s that capture the differential evolution in the outcome of tenure group $j$ after 2009, compared to that of almost unaffected groups, i.e. groups with 7, 12 or 23 months of tenure. ${ }^{17}$ Figure 7 plots the $\beta_{j}$ s of each tenure group against its corresponding change in PBD induced by the 2009 reform. In the upper

\footnotetext{
${ }^{16}$ Obviously, time-invariant characteristics only matter when we run specifications without individual fixed effects.

${ }^{17}$ Figure A5 in the Appendix plots these coefficients.
} 
panel, the reduced-form effects on the reservation wages are small in magnitude (below 0.01) and they do not seem to be related to the changes in PBD. This contrasts with the positive slope in the lower panel. The reduced-form effects on the actual benefit duration are positively related with the underlying change in PBD, and larger in magnitude. To sum up, Figure 7 suggests that UI generosity has no effect on reservation wages, while it affects unemployment duration.

Figure 7: Reduced form effects of the reform on the reservation wage and on the actual duration of benefits
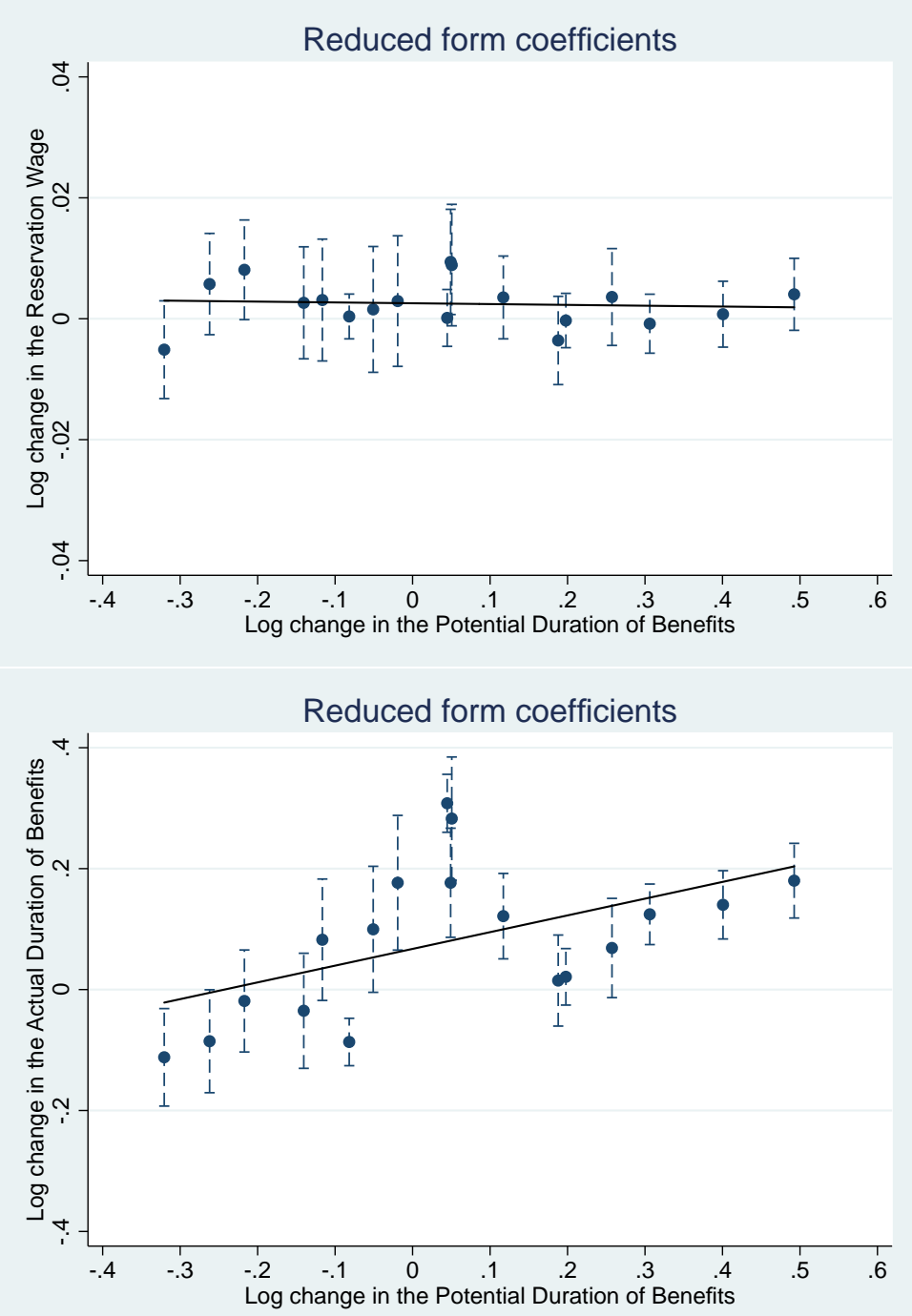

Source: FNA-FH (Pole emploi). Note: Each panel plots the reduced-form effects of the 2009 reform for various tenure group against its change in PBD. Each dot represent a tenure group. The reduced-form effects correspond to the $\beta_{j}$ 's estimated in Equation (3). The upper panel focuses on the reduced form effects on the reservation wage, the lower panel on the actual benefit duration. The vertical line around each dot corresponds to the $95 \%$ confidence interval. 


\subsection{Effect of PBD on the reservation wage and on the actual benefit duration}

Using the notations previously introduced, we estimate the following model:

$$
\begin{array}{r}
\log Y_{i, n}=\text { Indiv.F.E. }{ }_{\cdot}+\alpha \log P B D_{i, n}+\sum_{j=6, e x c l .7,12,23}^{26} \delta_{j} D\left(\text { Tenure }_{i, n}=j\right) \\
+\gamma X_{i, n}+\text { Year } \times \text { QuarterF.E. }+\epsilon_{i, n}
\end{array}
$$

Table 4 shows the elasticity estimates $(\alpha)$ of the reservation wage in the upper panel, and of the actual benefit duration in the lower panel. In Column (1), we report the elasticity estimated by OLS without individual fixed effects. In Column (2), we use the 2009 reform as an instrument for PBD. More precisely, we instrument $\log P B D_{i, n}$ by the set of tenure group dummies interacted with the dummy indicating that the reform has taken place: $\forall j \in[6,26], D$ (Tenure $\left._{i, n}=j\right) \times$ After $_{i, n}$. In Columns (3) and (4), we include individual fixed effects, respectively in the OLS and IV estimations. In Columns (5) and (6), we report the OLS and IV estimates on the full sample, without restricting it to multiple-spell job seekers, and consequently without fixed effects. Standard errors are robust and clustered by monthly tenure group in Columns (1) and (2).

\begin{tabular}{|c|c|c|c|c|c|c|}
\hline & $\begin{array}{c}\text { OLS } \\
(1)\end{array}$ & $\begin{array}{l}\text { IV } \\
(2)\end{array}$ & $\begin{array}{l}\text { FE } \\
(3)\end{array}$ & $\begin{array}{c}\mathrm{FE}, \mathrm{IV} \\
(4)\end{array}$ & $\begin{array}{c}\text { OLS } \\
(5)\end{array}$ & $\begin{array}{l}\text { IV } \\
(6)\end{array}$ \\
\hline & \multicolumn{6}{|c|}{ Log of reservation wage } \\
\hline \multirow[t]{2}{*}{$\log$ PBD } & 0.000954 & 0.00473 & -0.000132 & -0.000535 & $-0.00595^{*}$ & -0.00270 \\
\hline & $(0.00854)$ & $(0.00691)$ & $(0.00310)$ & $(0.00318)$ & $(0.00289)$ & $(0.00207)$ \\
\hline Obs. & 180,637 & 180,637 & 180,637 & 180,637 & $1,957,794$ & $1,957,794$ \\
\hline \multirow[t]{2}{*}{ R-squared } & 0.474 & & 0.340 & & 0.517 & \\
\hline & \multicolumn{6}{|c|}{ Log of actual benefit duration } \\
\hline \multirow[t]{2}{*}{$\log$ PBD } & $0.227^{* * *}$ & $0.232^{* * *}$ & $0.314^{* * *}$ & $0.306^{* * *}$ & $0.218^{* * *}$ & $0.220^{* * *}$ \\
\hline & $(0.0274)$ & $(0.0257)$ & $(0.0317)$ & $(0.0325)$ & $(0.0357)$ & $(0.0349)$ \\
\hline Obs. & 180,637 & 180,637 & 180,637 & 180,637 & $1,957,794$ & $1,957,794$ \\
\hline R-squared & 0.062 & & 0.095 & & 0.062 & \\
\hline Sample & \multicolumn{2}{|c|}{ multiple-spell } & \multicolumn{2}{|c|}{ multiple-spell } & \multicolumn{2}{|c|}{ full } \\
\hline Indiv. FE & no & no & yes & yes & no & no \\
\hline
\end{tabular}

Table 4: Elasticity of the reservation wage and benefit duration with respect to PBD

Source: FNA-FH (Pole emploi)

Note: Robust standard errors in parentheses. Standard errors clustered by monthly tenure group in Columns (1) to (4). ${ }^{* * *} \mathrm{p}<0.01,{ }^{* *} \mathrm{p}<0.05,{ }^{*} \mathrm{p}<0.1$. Individual controls, time fixed-effects and tenure fixed-effects are included in all specifications.

The estimates of the elasticity of the reservation wage are not statistically different from 
zero on the sample of multi-spell job seekers, whatever the specification. The estimation is very precise, especially when individual fixed effects are introduced. The standard errors in Columns (3) and (4) enable us to rule out that the elasticity is greater than 0.006 , i.e the upper bound of the $95 \%$ confidence interval. These findings are qualitatively identical on the full sample.

We perform placebo tests, detailed in Appendix Table A2. We consider four placebo reforms dates: end of March 2007, 2008, 2010 and 2011. None of the placebo reforms yields significant effects on the reservation wage, which supports the common trend assumption.

The absence of responsiveness of the reservation wage contrasts with that of the the actual benefit duration. The estimates of the actual benefit duration elasticity range from 0.22 in Columns (1) and (2) to 0.33 when individual fixed effects are introduced in Columns (3) and (4). All point estimates are statistically significant. The IV strategy hardly affects these estimates. Introducing individual fixed effects increases the elasticity estimates by $50 \%$. This points to positive selection into PBD. More productive individuals, who leave unemployment faster, tend to have longer PBD. Overall, our elasticities are in line with the literature: they are lower than the 0.5-0.6 elasticity reported in Schmieder et al. (2012a), but higher than the usual 0.1-0.2 estimates of the elasticity of non-employment duration.

Job seekers with higher PBD find jobs at a slower rate even in the first weeks of unemployment, period during which they declare their reservation wage. Table 5 shows the effect of PBD on the job finding probability during the first five weeks of unemployment. We report the estimate of $\alpha$ in equation (4), where we instrument PBD by the 2009 reform on the sample of recurrent job seekers - our preferred specification. In the $n$-th column of Table 5, the outcome variable is equal to one if the individual left the unemployment registers and declared having found a job within $n$ weeks after entering unemployment. After the very first week, PBD decreases significantly (at the 5\% level) the cumulative job finding rates: from 1 percentage point in week 2 to more than 2 percentage points in week 5. These results suggest that job seekers react to PBD from the very beginning of the unemployment spell and therefore that PBD is salient to them from the start. The absence of responsiveness of reservation wages cannot be attributed to an overall lack of reaction by the job seeker at the beginning of the spell.

\subsection{Effect of PBD on other dimensions of job selectivity}

Table 6 shows the effect of PBD on other job characteristics. We report the estimates of $\alpha$ in Equation (4) where the outcome is: a dummy indicating whether the job seeker looks for a long-term contract (Column 1), a dummy indicating whether she looks for a fulltime job (Column 2), a composite measure of the willingness of the job seeker to commute 
Table 5: Effect of PBD on cumulative job finding rates at the beginning of the unemployment spell

\begin{tabular}{lccccc}
\hline & \multicolumn{5}{c}{ Cumulative job finding rate } \\
\# of weeks & 1 & 2 & 3 & 4 & 5 \\
since U entry & & & & & \\
\hline log PBD & -0.00778 & $-0.0130^{* *}$ & $-0.0165^{* *}$ & $-0.0195^{* *}$ & $-0.0234^{* * *}$ \\
& $(0.00459)$ & $(0.00594)$ & $(0.007703)$ & $(0.00789)$ & $(0.00862)$ \\
Average outcome & 0.018 & 0.030 & 0.044 & 0.057 & 0.070 \\
Indiv. FE & yes & yes & yes & yes & yes \\
Obs. & 180,637 & 180,637 & 180,637 & 180,637 & 180,637 \\
\hline
\end{tabular}

Source: FNA-FH (Pole emploi)

Note: Robust standard errors in parentheses. ${ }^{* * *} \mathrm{p}<0.01,{ }^{* *} \mathrm{p}<0.05,{ }^{*} \mathrm{p}<0.1$. The Table reports the coefficient $\alpha$ of Eq. 4, where we instrument PBD by the 2009 reform. Individual controls, time fixed-effects and tenure fixed-effects are included. The specification corresponds to that of column (4) in Table 4.

(Column 3). We use our preferred specification, with the 2009 reform as an instrument and controlling for individual fixed effects (and covariates).

At registration, job seekers can answer the question about mobility in terms of commuting time or commuting distance. In Column (3), we use as an outcome the log of the commuting time or commuting distance, controlling the declaration unit (kilometers or minutes).

Table 6 does not display any statistically significant coefficient relating to PBD. We can rule out small effects of PBD on these extra dimensions of job selectivity. For example, a 10\% increase in PBD cannot trigger effects larger than 0.08 percentage points on the probability to look for a long-term contract. These results are robust when we estimate the model by OLS, with or without fixed effects (results available upon request).

Table 6: Effect of PBD on other dimensions of job selectivity

\begin{tabular}{lccc}
\hline & \multicolumn{2}{c}{ Looking for a } & \multicolumn{2}{c}{ Max. commuting } \\
& $\begin{array}{c}\text { long-term contract } \\
(1)\end{array}$ & $\begin{array}{c}\text { full-time job } \\
\text { time/distance (log) }\end{array}$ & $(3)$ \\
\hline $\log$ PBD & -0.00462 & 0.000111 & -0.000931 \\
& $(0.00825)$ & $(0.00496)$ & $(0.0132)$ \\
Indiv. FE & yes & yes & yes \\
Obs. & 180,637 & 180,637 & 163,192 \\
\hline
\end{tabular}

Source: FNA-FH (Pole emploi)

Note: Robust standard errors in parentheses. ${ }^{* * *} \mathrm{p}<0.01,{ }^{* *} \mathrm{p}<0.05,{ }^{*} \mathrm{p}<0.1$. The Table reports the coefficient $\alpha$ of Eq. 4, where we instrument PBD by the 2009 reform. Individual controls, time fixed-effects and tenure fixed-effects are included. The specification corresponds to that of column (4) in Table 4. There are missing values in Column (3) because the mobility question is not mandatory. 


\subsection{Heterogeneity analysis}

In this section, we analyze the heterogeneity of the effect and we show that job seekers who have a tenure lower than the median and who thus face a shorter horizon before benefit exhaustion react more to changes in PBD.

When the heterogeneity of the effect relates to time-invariant characteristics, we directly use the fixed-effect specification in stratified samples. For characteristics such as tenure or past wage which can vary across spells within individuals, we compute the average within individuals across spells and split the sample at the median of this average value.

Table 7 reports the estimates of the PBD elasticity of the reservation wage (upper panel) and of the actual benefit duration (lower panel) in various sub-samples. The elasticity estimates are obtained according to our preferred estimation strategy, instrumenting PBD with the 2009 reform and controlling for individual fixed effects. Column (1) reports the elasticity estimates for job seekers with an average past tenure below the median, which is 13 months. Their elasticity of the reservation wage is around 0.01 , and statistically significant. They react more to changes in PBD presumably because their horizon before benefit exhaustion is shorter : they face on average a PBD of 9 months whereas the average PBD of job seekers with a past tenure above the median is 18 months. Consistently, the elasticity of the actual benefit duration is higher for job seekers with lower tenure (Column 1) than for job seekers with higher tenure (Column 2).

Note that the positive correlation between PBD elasticities of reservation wages and of unemployment duration does not contradict the negative correlation between elasticities of accepted wages and of unemployment duration highlighted in Nekoei and Weber (2017). Indeed, negative duration dependence in unemployment does not drive down the elasticity of reservation wage measured at the beginning of the spell.

When restricting our sample to claimants with low tenure, we analyze a sub-population that experience a PBD shock closer to Nekoei and Weber (2017). They focus on 40-year-old claimants who experience a PBD increase from 30 to 39 weeks. Our reservation wage elasticity on the low-tenure sub-population (.01) is then in line with their elasticity of accepted wages (.016). ${ }^{18}$ That being said, we still expect elasticities on reservation wages to be higher than elasticity on accepted wages, as unemployment duration, which is increased by UI, affects negatively job offer prospects.

We do not find any difference in the elasticity of the reservation wage across gender (Column (3) vs. Column (4) in Table 7). In the lower panel, the elasticity of the actual benefit duration is higher for females than for males -a standard result in the literature on labor

\footnotetext{
${ }^{18}$ Nekoei and Weber (2017) report that reemployment wages increase by .5\% (Table 2 of their paper) when PBD increases from 30 to 39 weeks (30\%).
} 
supply-, although the difference in elasticity is not statistically significant. Lastly we do not find any difference in the elasticity of the reservation wage and of the actual benefit duration, between low-wage and high-wage job seekers (Column (5) vs. Column (6)). This is surprising as we would expect higher wage workers to be less constrained by the minimum wage and thus to respond more to changes in PBD. However, high-wage job seekers probably have higher job finding rates and higher past tenure, which also makes them less responsive to changes in $\mathrm{PBD}$.

Table 7: Heterogeneity analysis

\begin{tabular}{|c|c|c|c|c|c|c|}
\hline & \multicolumn{2}{|c|}{ Tenure } & \multicolumn{2}{|c|}{ Gender } & \multicolumn{2}{|c|}{ Past wage level } \\
\hline & $\begin{array}{c}\text { Low tenure } \\
\text { (1) }\end{array}$ & $\begin{array}{l}\text { High tenure } \\
\text { (2) }\end{array}$ & $\begin{array}{c}\text { Female } \\
\text { (3) }\end{array}$ & $\begin{array}{c}\text { Male } \\
(4)\end{array}$ & $\begin{array}{l}\text { Low wage } \\
\text { (5) }\end{array}$ & $\begin{array}{l}\text { High wage } \\
\text { (6) }\end{array}$ \\
\hline \multirow{4}{*}{$\log$ PBD } & \multicolumn{6}{|c|}{ Log of Reservation wage } \\
\hline & $0.00964^{* *}$ & -0.00272 & 0.00156 & -0.00245 & 0.00323 & -0.00285 \\
\hline & $(0.00379)$ & $(0.00557)$ & $(0.00454)$ & $(0.00435)$ & $(0.00340)$ & $(0.00543)$ \\
\hline & \multicolumn{6}{|c|}{ Log of Actual Benefit duration } \\
\hline \multirow{2}{*}{$\log \mathrm{PBD}$} & $0.514^{* * *}$ & $0.202^{* * *}$ & $0.332^{* * *}$ & $0.292^{* * *}$ & $0.321^{* * *}$ & $0.291^{* * *}$ \\
\hline & $(0.0399)$ & $(0.0558)$ & $(0.0508)$ & $(0.0423)$ & $(0.0448)$ & $(0.0473)$ \\
\hline Obs. & 90,364 & 90,273 & 72,472 & 108,165 & 90,203 & 90,434 \\
\hline Indiv. F.E. & yes & yes & yes & yes & yes & yes \\
\hline
\end{tabular}

\section{Alternative empirical strategy: Regression Discontinuity De- sign}

In this section, we consider an alternative identification strategy based on an age discontinuity in Potential Benefit Duration (PBD) at age 50.

When workers are above 50 years old at the time of job separation, they benefit from a more generous PBD schedule. Before 2009, when senior claimants had worked more than 27 months during the last 36 months, they were entitled to 1,095 days of benefits, i.e. 36 months. If they did not fulfill this criteria, they faced the step function schedule described in Section 2. Starting in 2009, senior workers are entitled to as many days of benefits as days worked within the last 36 months before job separation: the maximum PBD is thus 36 months. Consequently, senior workers with continuous work history over the last 3 years before unemployment are entitled to benefits for a period that is $50 \%$ longer than that of younger workers. Besides this difference in PBD schedule, UI rules are essentially the same 
for claimants above and below 50 years old. In particular, the formula used to compute the amount of benefits as a function of past wages is identical for senior and younger workers.

We select a sample of new claims filed between 2006 and 2012. We apply the same sample restrictions as above, but do not restrict the sample to job seekers with multiple claims over the period. We only keep claims filed by job seekers aged between 45 and 55, which corresponds to a 10-year window around the RDD cutoff. In our sample, we estimate that PBD is on average around 30\% higher for claimants above 50 than below 50 .

Figure 8 plots the distribution of the population in age bins that are one-month wide. This reveals some missing mass just below 50 and extra mass just above the cutoff. We perform the usual McCrary test and we estimate that the density is $8 \%$ higher just above the cutoff - statistically significant at the $1 \%$ level. ${ }^{19}$

Figure 8: Distribution of the running variable (age in month)

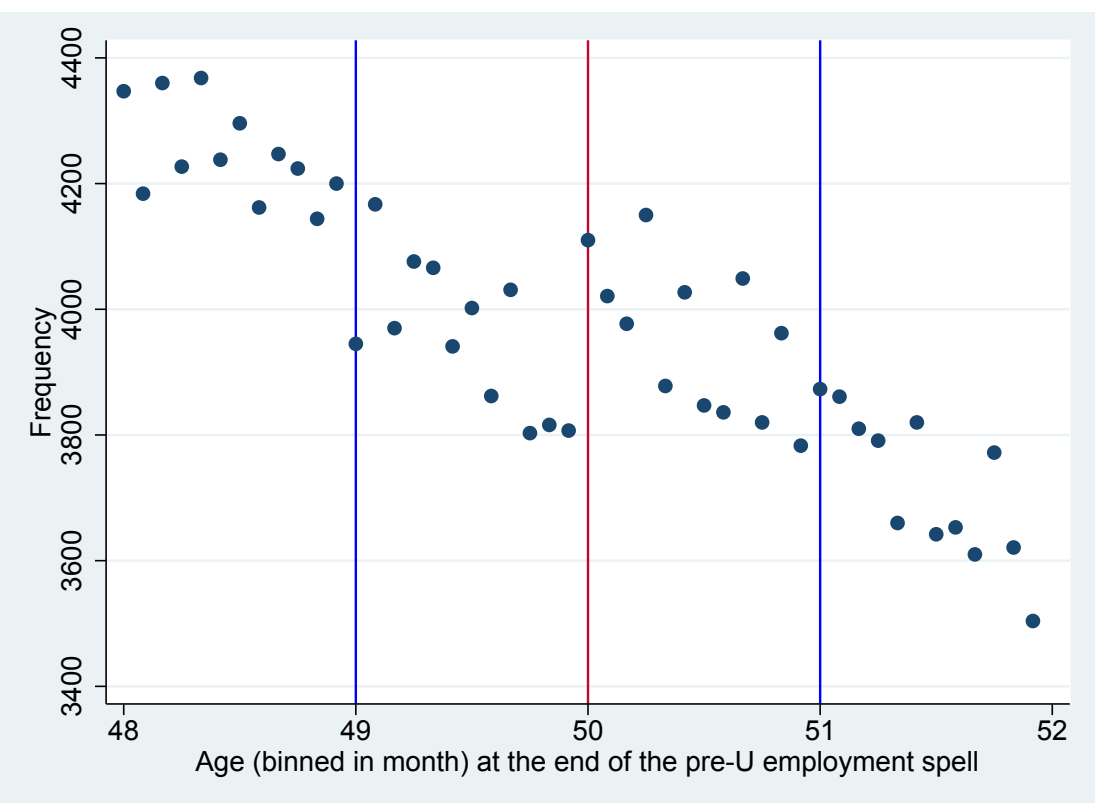

We also find some discontinuities in the distribution of covariates around the threshold. Appendix Table A3 shows that workers laid off just after 50 years old are more educated and are paid higher wages. This is consistent with some manipulation of the running variable, i.e. age at the separation date. Manipulation is a serious threat to the RDD identification strategy. This is the reason why we only consider the RDD as an alternative strategy and the next results as suggestive. Yet we find it reassuring that they are consistent with the main results obtained with the difference-in-difference strategy.

\footnotetext{
${ }^{19}$ The bandwidth used to perform the test is around 2 years.
} 
Lalive (2007) and Schmieder et al. (2012a) also report cases of manipulation in the context of UI rules based on age. To address this issue, we follow the same strategy as Schmieder et al. (2012a) and we exclude the observations that are just around the age cutoff. ${ }^{20}$ This is a valid correction as long as manipulation is a local matter. There are no theoretical guidelines to choose the size of the window around the cutoff where we exclude observations. Visual inspection of the density of the running variable plotted in Figure 8 suggests that the manipulation window would be between 3 months before and 3 months after the cutoff. We vary the size of the window to test the robustness of our estimates.

Figure 9 plots PBD and the outcomes of interest against age at job separation excluding individuals between 49.75 and 50.25 years old. The upper panel shows that the distribution of reservation wages seems continuous on either side of the cutoff whereas the lower panel shows that the size of the discontinuity in PBD is around $30 \%$ as already mentioned above and that there is a discontinuity in the actual duration of benefits at the cutoff.

For the estimation, we consider the fuzzy RD design where the treatment is the log of PBD. This framework enables us to interpret our estimates as elasticities with respect to PBD. We estimate the following model using the dummy 1 (age $\geq 50)$ indicating that the claimant is over 50 years old (at job separation) as an instrument.

$$
\log Y_{i}=\alpha+\delta \log P B D+P_{0}\left(a g e_{i}-50\right) \times 1\left(a g e_{i}<50\right)+P_{1}\left(a g e_{i}-50\right) \times 1\left(a g e_{i} \geq 50\right)+\epsilon_{i}
$$

where $P_{0}($.$) and P_{1}($.$) are polynomials whose coefficients are estimated (without constant).$ We follow the common practice and we use local polynomial regression. The bandwidth of the local estimation is selected according to Calonico et al. (2014). We also follow the methods they recommend for bias correction and robust standard error correction.

Table 8 reports the estimates of the elasticities $\delta$ on samples trimmed in different ways (see columns). The upper panel reports the estimates of the elasticity of the reservation wage, while the lower panel reports those of the elasticity of the actual benefit duration. The elasticity of the reservation wage is not statistically significant, whatever the size of the excluded region around the cutoff. This contrasts with the elasticity of benefit duration, which is around 0.2 and statistically different from zero. This confirms the main results of Section 4: inelastic reservation wage and responsive benefit duration. We also find that the effects of PBD on other dimensions of the reservation strategy, such as the desired type of labor contract or number of hours or the maximum commute accepted, are not statistically different from zero (results available on request).

\footnotetext{
${ }^{20}$ Lalive (2007) finds that only women manipulate their age to benefit from more generous entitlement.
} 
Figure 9: Regression Discontinuity graphics, excluding observations with age between 49.75 and 50.25 .

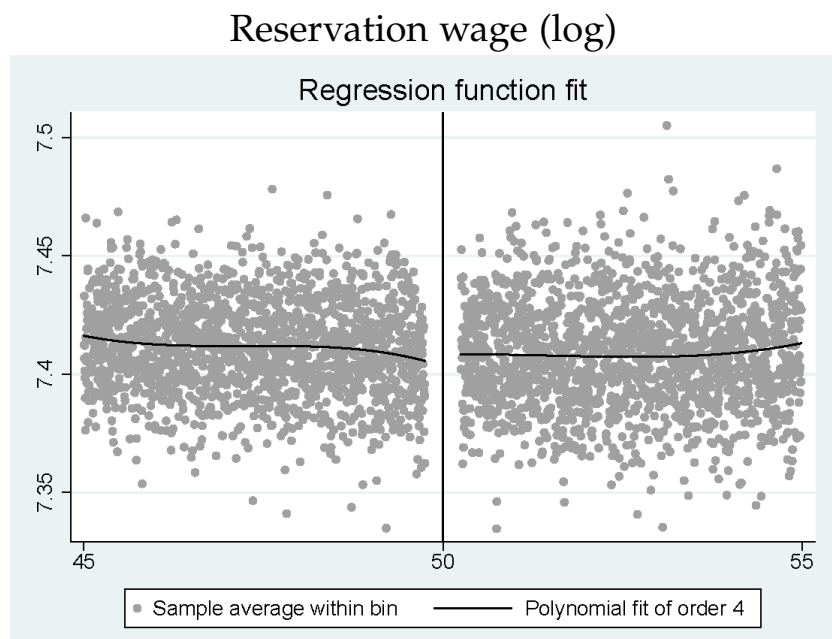

Potential Benefit Duration (log)

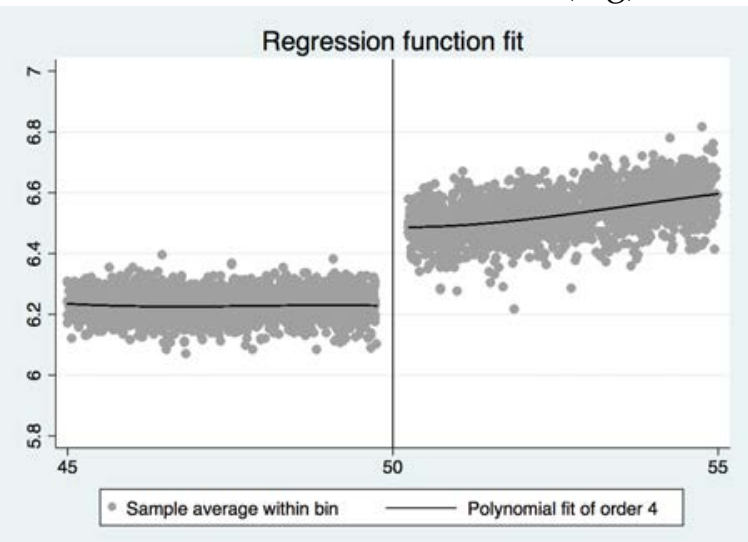

Benefit duration (log)

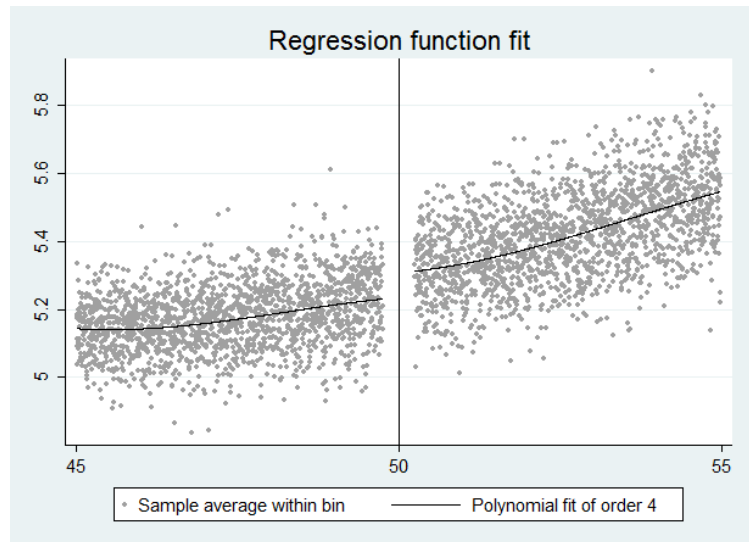

Source: FNA-FH (Pole emploi).

Note: plots are obtained with the stata command rdplot. The data is grouped in age bins, whose size is determined according to Calonico et al. (2014). For each age bin, we plot the averages of the reservation wage, of PBD and of the actual benefit duration. Then a polynomial of degree 4 is fitted on these averages - the solid line. 
Table 8: RDD estimates of elasticities wrt PBD

\begin{tabular}{lccc}
\hline Age & $(1)$ & $(2)$ & $(3)$ \\
excluded & {$[49.9,50.1]$} & {$[49.75,50.25]$} & {$[49.5,50.5]$} \\
\hline \multirow{4}{*}{ Log of Reservation wage } \\
log PBD & 0.0116 & 0.0172 & 0.00457 \\
& $(0.0149)$ & $(0.0162)$ & $(0.0141)$ \\
& Log of Actual benefit duration \\
log PBD & $0.211^{* * *}$ & $0.242^{* * *}$ & $0.175^{* *}$ \\
& $(0.0786)$ & $(0.0669)$ & $(0.0692)$ \\
\hline Obs. & 470,082 & 456,280 & 432,431 \\
\hline
\end{tabular}

Source: FNA-FH (Pole emploi).

Note: Standard errors in parentheses. ${ }^{* * *} \mathrm{p}<0.01,{ }^{* *} \mathrm{p}<0.05,{ }^{*} \mathrm{p}<0.1$.

Note: The reported coefficients are the estimated $\delta$ from equation (5).

The estimation follows Calonico et al. (2014). The kernel used for local polynomial estimation is triangular.

Appendix Table A3 tests for discontinuities in covariates, when observations around the threshold are excluded. Any discontinuities disappear as the bandwidth of the trimmed sample around the cutoff increases. In Appendix Table A4, we further show that including covariates as controls in the RDD estimation hardly affects the estimated elasticities reported in Table 8. Finally, we conduct placebo tests at every age from 44 to 54 . Appendix Table A5 shows no significant discontinuities at every placebo age.

\section{Interpretation}

In a simple job search model, the job finding rate (or hazard rate) $h$ is the product of the probability to receive an offer $e$ and the probability to accept this offer given one's reservation wage $\psi$.

$$
h=e \bar{F}(\psi)
$$

where $F($.$) is the cumulative distribution function of wage offers.$

When the potential benefit duration $T$ changes, the probability to receive an offer may change, as job seekers adjust their search effort. The probability to accept the offer may change as well, as job seekers update their reservation wages. Given equation (6), there exists a mechanical relationship between the elasticities of $h, e$ and $\psi$ with respect to the potential benefit duration.

$$
\epsilon_{h, T}=\epsilon_{e, T}-\frac{f(\psi) \psi}{\bar{F}(\psi)} \epsilon_{\psi, T}
$$

where $\epsilon_{y, T}$ is the elasticity of variable $y$ with respect to the potential benefit duration $T$, and 
$f($.$) is the density of wage offers.$

Using equation (7), we would like to assess the extent to which the elasticity of the reservation wage explains the elasticity of the hazard rate. For this empirical exercise, we will use the elasticities $\hat{\epsilon}_{h, T}$ and $\hat{\epsilon}_{\psi, T}$ we have estimated in the previous sections, as well as the distribution of wages obtained by job seekers newly employed. ${ }^{21}$ Taking the average value of the reservation wage, we find that the empirical equivalent of $\psi f(\psi) / \bar{F}(\psi)$ is close to $3 .^{22}$ For the empirical value of the elasticity of the hazard rate to potential benefit duration, we can either consider the elasticity of unemployment duration (Table 4, column 4, second panel), or the elasticity of the job finding rate in the first weeks of the spell (Table 5). Both give a value of $\hat{\epsilon}_{h, T}$ around $-.3 .{ }^{23}$ Taking the upper bound value of the $95 \%$ confidence of the elasticity of $\hat{\epsilon}_{\psi, T}$, equal to .006 , we find that the response of the reservation wage (-.018) represents at most $6 \%$ of the elasticity of the hazard rate $\left(\hat{\epsilon}_{h, T}=-.3\right)$, so that the search margin would represent at least $94 \%$. Considering the median reservation wage instead of the mean leads to an even smaller role for the reservation wage: at most $3.5 \%$.

\section{Conclusion}

Despite a significant and non negligible effect of the Potential Benefit Duration (PBD) on actual benefit duration, there is almost zero effect of PBD on the reservation wage and other dimensions of job selectivity at the start of the unemployment spell. The elasticity of reservation wages is insignificant and we can rule out that it is larger (in absolute value) than 0.006 , which means that being entitled to 1 additional month of benefits for a claimant with an initial PBD of 10 months is associated with at most a $0.06 \%$ increase in the reservation wage. The lack of responsiveness of reservation wages to changes in UI echoes the results of Krueger and Mueller (2016) who find that reservation wages adjust at a very slow rate along the unemployment spells.

The question of why reservation wages react so little to changes in UI remains open. We see at least two explanations that are worth further explorations. First, job seekers may have reference-dependent behaviors (Koenig et al., 2014; DellaVigna et al., 2016). They may anchor their reservation wages on their past wages, which would limit the responsiveness of reservation wages. Second, job seekers may have biased beliefs about their employment prospects. Over-optimistic job seekers, who consider that job offers arrive at a high arrival

\footnotetext{
${ }^{21}$ Because we work on claimants with multiple spells, we can observe in the administrative data the past wage relating to the second unemployment spell, which we consider a good proxy for the hiring wage after the first unemployment spell.

${ }^{22}$ We take $\psi=1.2$, i.e. $20 \%$ higher than the legal minimum wage, and we find in the empirical distribution of wages that $f(1.2)=1.92$ and $\bar{F}(1.2)=.76$.

${ }^{23}$ Considering the elasticity of unemployment duration gives $\hat{\epsilon}_{h, T}=.306$. Considering the elasticity of the job finding rate, for example in the three first weeks, gives $\hat{\epsilon}_{h, T}=-.0165 / .044=-.375$.
} 
rate, might also react too little to changes in $\mathrm{PBD}$, as they underestimate their likelihood to exhaust benefits (Spinnewijn, 2015). Exploring these possibilities are promising directions for future work.

A last natural question concerns the extent to which empirical measures of reservation wages inform us about the welfare cost of unemployment (Shimer and Werning, 2007). Answering this question is essential in order to assess how useful our elasticity of reservation wage is to the design of optimal UI.

\section{References}

Calonico, S., M. D. Cattaneo, and R. Titiunik (2014): "Robust Nonparametric Confidence Intervals for RegressionDiscontinuity Designs," Econometrica, 82, 2295-2326.

Card, D., R. Chetty, and A. Weber (2007): “The Spike at Benefit Exhaustion: Leaving the Unemployment System or Starting a New Job?" American Economic Review, 97, 113-118.

DellaVigna, S., A. Lindner, B. Reizer, ANd J. F. Schmieder (2016): “Reference-Dependent Job Search: Evidence from Hungary," NBER Working Papers 22257, National Bureau of Economic Research, Inc.

Feldstein, M. ANd J. Poterba (1984): “Unemployment insurance and reservation wages," Journal of Public Economics, 23, 141-167.

Koenig, F., A. Manning, and B. Petrongolo (2014): "Reservation Wages and the Wage Flexibility Puzzle," CEP Discussion Papers dp1319, Centre for Economic Performance, LSE.

Krueger, A. B. ANd A. I. Mueller (2016): "A Contribution to the Empirics of Reservation Wages," American Economic Journal: Economic Policy, 8, 142-79.

Lalive, R. (2007): “Unemployment Benefits, Unemployment Duration, and PostUnemployment Jobs: A Regression Discontinuity Approach," American Economic Review, 97, 108-112.

Lalive, R., C. Landais, And J. Zweimueller (2015): “Market Externalities of Large Unemployment Insurance Extension Programs," American Economic Review, 105, 3564-96.

Le Barbanchon, T. (2016): "The Effect of the Potential Benefit Duration of Unemployment Benefits on Unemployment Exits to Work and Match Quality in France," Labor Economics, $16-29$.

Lichter, A. (2016): "Benefit duration and Job search effort: Evidence from a Natural Experiment," unpublished.

McCALL, J. J. (1970): “Economics of Information and Job Search," The Quarterly Journal of Economics, 84, 113-26. 
Nekoei, A. ANd A. Weber (2017): “Does Extending Unemployment Benefits Improve Job Quality?" American Economic Review, 107, 527-61.

SCHMIEDER, J. F. AND T. vON WACHTER (2016): “The Effects of Unemployment Insurance: New Evidence and Interpretation," Annual Review of Economics, forthcoming.

Schmieder, J. F., T. von WACHTER, AND S. Bender (2012a): “The Effects of Extended Unemployment Insurance Over the Business Cycle: Evidence from Regression Discontinuity Estimates Over 20 Years," The Quarterly Journal of Economics, 127, 701-752.

(2012b): "The Long-Term Effects of UI Extensions on Employment," American Economic Review, 102, 514-19.

(2016): "The Effect of Unemployment Benefits and Nonemployment Durations on Wages," American Economic Review, 106, 739-77.

Shimer, R. ANd I. Werning (2007): "Reservation Wages and Unemployment Insurance," The Quarterly Journal of Economics, 122, 1145-1185.

SpinnewiJn, J. (2015): “Unemployed But Optimistic: Optimal Insurance Design With Biased Beliefs," Journal of the European Economic Association, 13, 130-167. 


\section{A Appendix: Consequences of rounding}

In this Appendix, we discuss the consequences of rounding in the reservation wages on our identification. First, we explore potential biases taking an analytical perspective. Second, we quantify its importance using Monte-Carlo simulations.

We are not in the standard case of classical measurement error in a covariate. We consider measurement error on the reservation wage, which is the main outcome (left-hand side variable), and rounding is a non-classical measurement error, as the difference between the true variable and its proxy is not independent of the true running variable.

First, we clarify the potential bias from an analytical perspective. We denote $Y^{*}$ the true unobserved outcome. We assume that we only observe $Y$, obtained after rounding to the nearest hundreds. We have $Y=v+Y^{*}$, where $v=Y-Y^{*}$ is the measurement error. We assume that the true data generating process is such that: $Y^{*}=\beta X+u$ where $Y^{*}$ and $X$ are centered and $u$ is an error term uncorrelated to $X$. Because of the measurement error, we can only estimate the following model: $Y=\tilde{\beta} X+w$. After some algebra, the OLS estimate of $\beta$ is $\tilde{\beta}=\beta+\frac{\operatorname{cov}(v, X)}{\operatorname{var}(X)}$. The measurement error will induce a bias if and only if the rounding error $v$ is correlated with $X$ (i.e. PBD in our case), which has a priori no reason to be true.

Second, we run some simulations to check what happens in practice with plausible data generating processes. We draw the PBD in $1+7 U^{1 / 2}$, where $U$ is a uniform between 0 and 1, which generates a Pareto between 8 and 24, and the wage is a log-normal with the first and last deciles equal to 800 and 3700. We set the elasticity of the wage to PBD to 0.2. Then, we build a version of the wage rounded to the hundreds. For the Monte-Carlo simulation, we generate 1,000 samples of size 10,000. For each sample, we estimate the elasticity of the wage wrt PBD and the elasticity of the rounded wage wrt PBD. Figure A1 shows the distributions of the elasticity estimates without and with rounding: both distributions look extremely similar. In Figure A2, we compute for each simulation the difference between elasticity estimates with and without rounding - the bias - and we plot the distribution of biases. The bias is very close to zero (magnitude 100 times lower than the original elasticity). The measurement error induced by rounding the outcome is likely not to be a first-order issue in our case. 
Figure A1: Monte-Carlo simulations: distribution of elasticity estimates

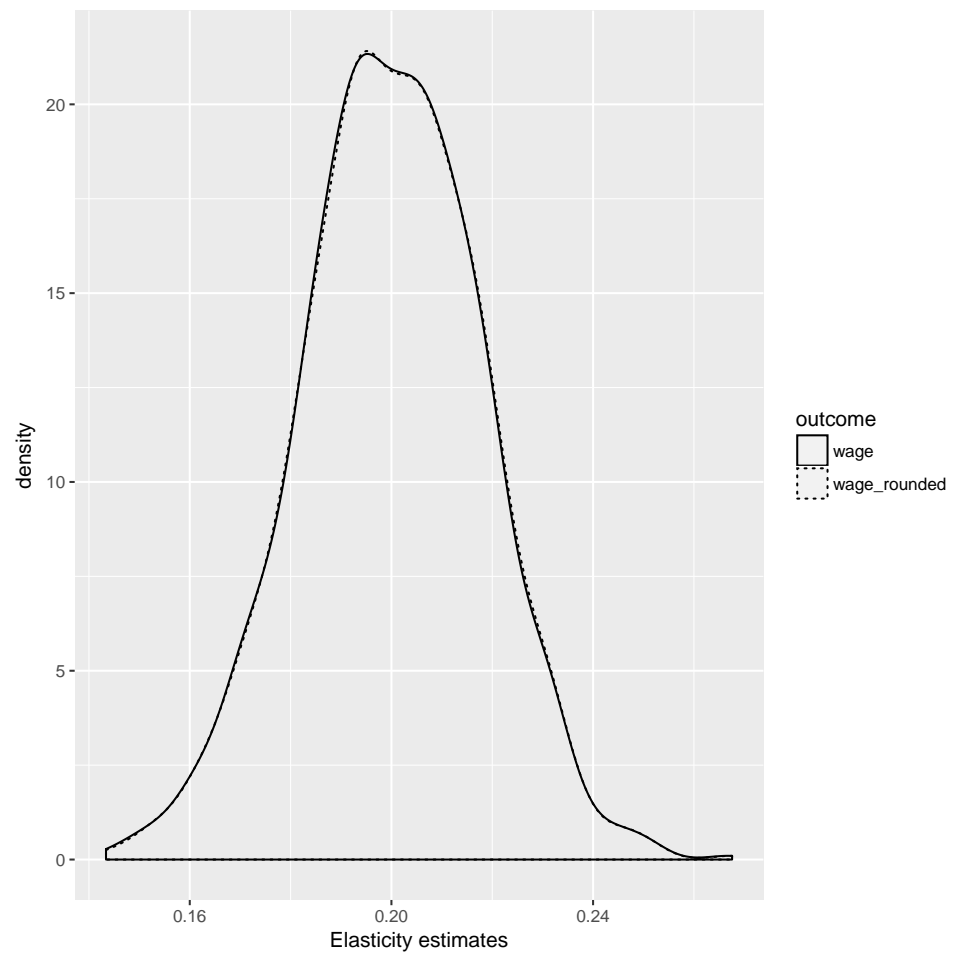

Figure A2: Monte-Carlo simulations: distribution of bias

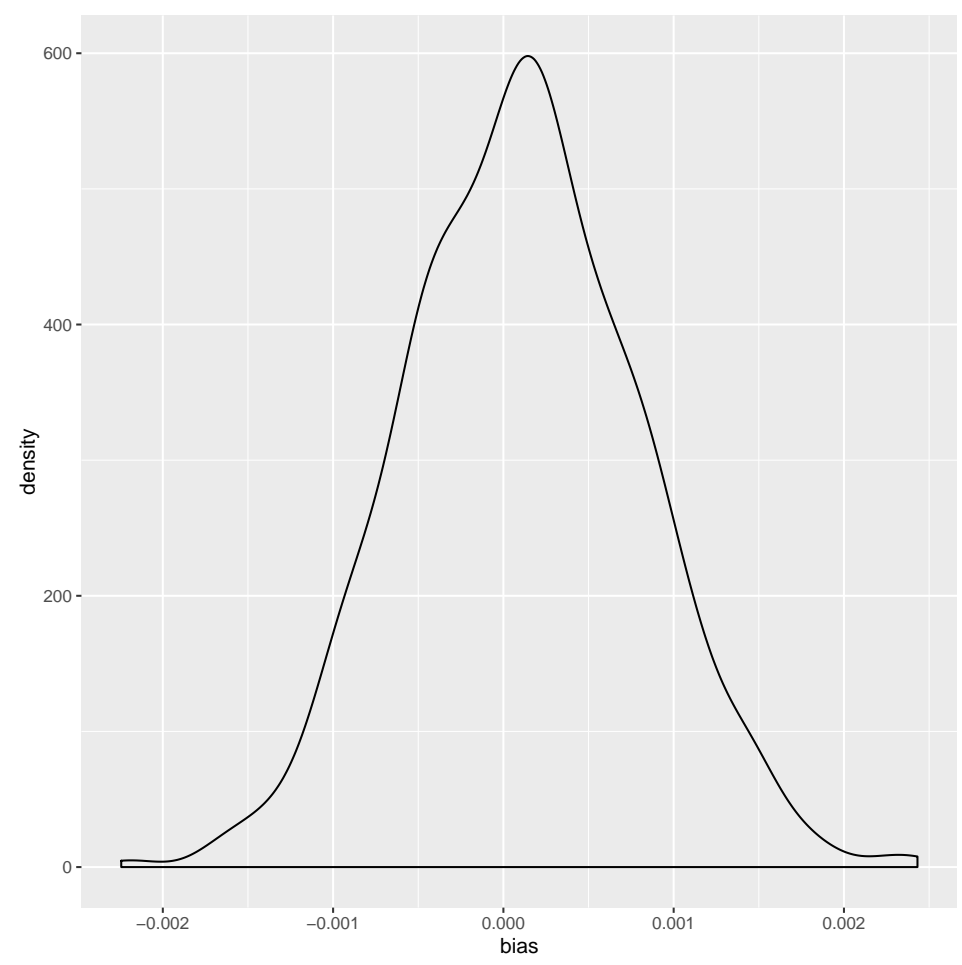




\section{B Appendix: Figures}

Figure A3: Distribution of the tenure variables
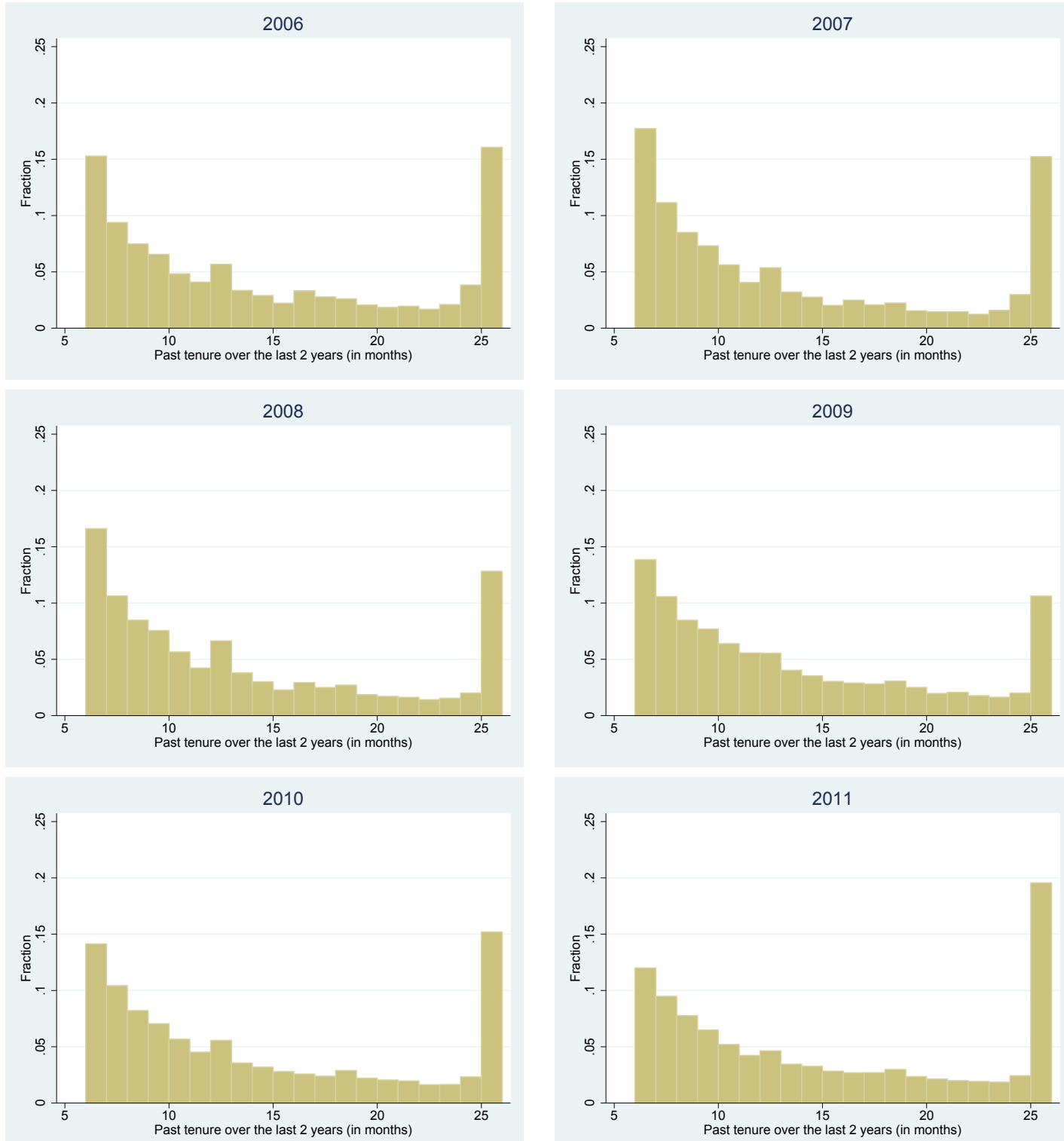

Source: FNA-FH (Pole emploi). Note: Each panel plots the distribution of the past tenure for the inflow of claimants who loose their job between the 1st of April of year $\mathrm{N}$ and the 31st of March of Year $\mathrm{N}+1$. Thus the 3 first distributions are pre reform and the 3 last are post reform. 
Figure A4: Average PBD given 2006 and 2009 rules

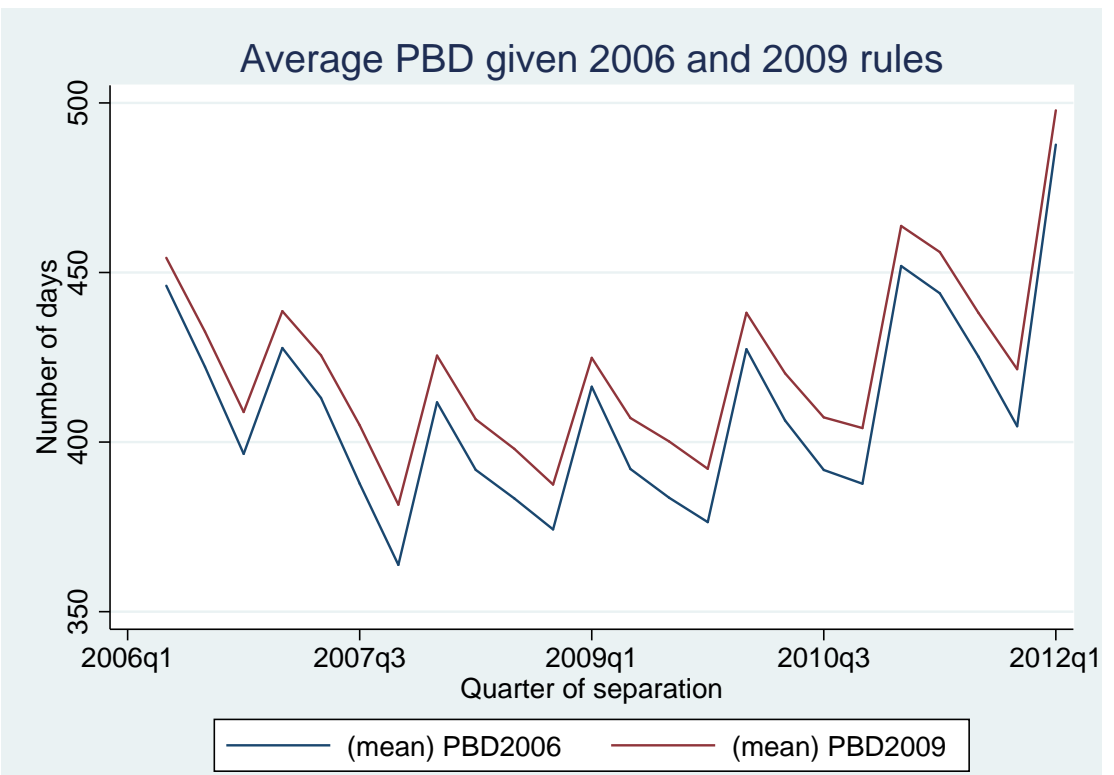

Source: FNA-FH (Pole emploi). Note: for each claimant, we compute, from her tenure, her PBD according to the 2006 rules and the 2009 rules. We then average each PBD over quarter. This translates the actual tenure distribution into potential treatment intensity. The Figure shows that there are no changes in the tenure distribution that would imply a change in treatment intensity on top of the reform shock. 
Figure A5: Reduced form effect of the reform on the reservation wage and on the actual duration of benefits

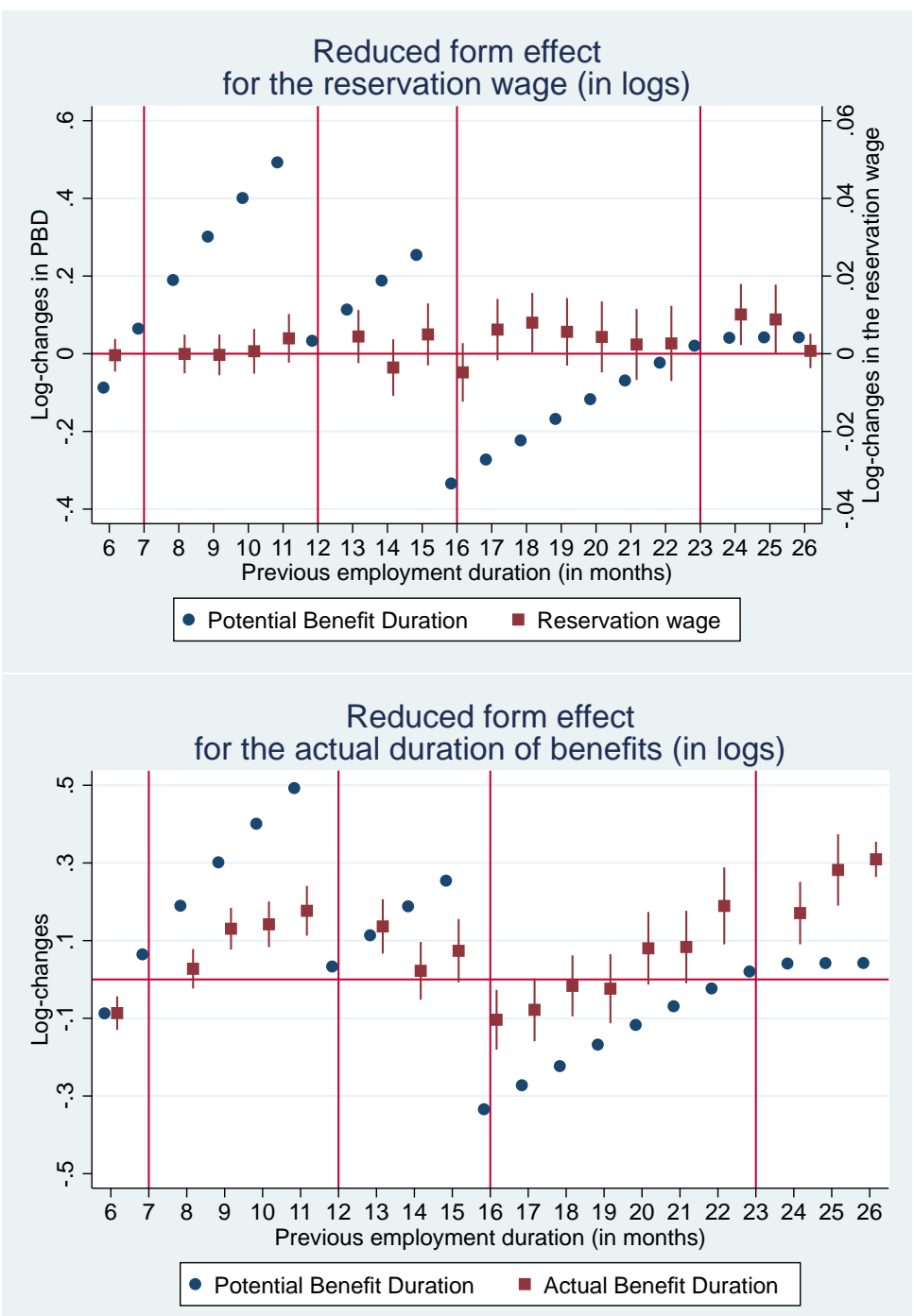

Source: FNA-FH (Pole emploi). Note: Each panel plots the change in PBD for every tenure group (circles in blue) and the reduced-form effects (squares in red) on either the reservation wage (upper panel) and the actual benefit duration (lower panel). The reduced-form effects correspond to the $\beta_{j}$ coefficients, where $j$ indicates the group with $j$ months of tenure, from the following regression.

$$
\begin{aligned}
\log Y_{i, n}=\sum_{j=6, e x c l .7,12,23}^{26} \beta_{j} D\left(\text { Tenure }_{i, n}=j\right) \times \text { After }_{i, n}+ & \sum_{j=6, \text { excl. } 7,12,23}^{26} \delta_{j} D\left(\text { Tenure }_{i, n}=j\right) \\
& +\gamma X_{i, n}+\gamma \text { ear } \times \text { QuarterF.E. }+ \text { Indiv.F.E. } \cdot i+v_{i, n}
\end{aligned}
$$

$Y_{i, n}$ is either the reservation wage or the number of days of benefit receipt for the $\mathrm{n}$-th claim of individual i. $X_{i, n}$ controls for the job seeker's observable characteristics. These include gender, age and experience, age square and experience square, number of years of schooling, marital status and number of children, a dummy for being foreign born, and dummies for 20 bins of the previous wage. We also include dummy variables for the year $\times$ quarter at which the previous job ended. 


\section{Appendix: Tables}

Table A1: Summary statistics

\begin{tabular}{lccc}
\hline \multicolumn{1}{c}{ Variable } & Mean & Std. Dev. & N \\
\hline Male & 0.599 & 0.49 & 180670 \\
Foreign born & 0.111 & 0.314 & 180670 \\
Age & 31.301 & 7.873 & 180670 \\
Married & 0.353 & 0.478 & 180670 \\
Divorced & 0.068 & 0.252 & 180670 \\
Has a child & 0.363 & 0.481 & 180670 \\
Education (in years) & 11.59 & 3.272 & 180637 \\
Occupational Experience (in years) & 4.628 & 5.149 & 180670 \\
Past Contract is long-term & 0.353 & 0.478 & 166486 \\
Sum of past tenures over the last 2 years (in days) & 427.708 & 218.351 & 180670 \\
Past tenure at last employer (in days) & 393.648 & 573.158 & 180670 \\
Potential Benefit Duration (in days) & 413.156 & 208.855 & 180670 \\
Actual Benefit Duration (in days) & 192.403 & 163.184 & 180670 \\
Past Monthly Wage (gross, in euros) & 1721.631 & 388.383 & 180670 \\
Unemployment Benefits (in euros) & 1006.869 & 226.521 & 180670 \\
\hline Source: FNA-FH (Pole emploi). & & &
\end{tabular}

Table A2: Placebo elasticities - DiD strategy

\begin{tabular}{lcccc}
\hline & $(1)$ & $(2)$ & $(3)$ & $(4)$ \\
VARIABLES & 2007 & 2008 & 2010 & 2011 \\
Log of reservation wage & \\
\hline \multirow{5}{*}{ Log PBD } & 0.00979 & 0.00709 & 0.00755 & 0.00512 \\
& $(0.00655)$ & $(0.00654)$ & $(0.00582)$ & $(0.00566)$ \\
Obs. & 30,603 & 30,603 & 36,422 & 36,422 \\
Indiv. F.E. & yes & yes & yes & yes \\
\hline
\end{tabular}

Source: FNA-FH (Pole emploi).

Note: Robust standard errors in parentheses. ${ }^{* * *} \mathrm{p}<0.01,{ }^{* *} \mathrm{p}<0.05,{ }^{*} \mathrm{p}<0.1$. This Table reports the placebo tests. To avoid contamination, we split our main sample into two subsamples: before and after the 2009 reform. We use the before subsample to test for potential effects of placebo reforms at the end of March 2007 (Column 1) and of March 2008 (Column 2). We use the after subsample in Columns (3) and (4). In each column, we estimate the fixed effects model (2) where we replace actual PBD by a placebo PBD and we instrument the placebo PBD by tenure group dummies interacted with a dummy indicating whether the separation date is after the placebo reform date. For example, in Column (1), the placebo PBD is equal to the PBD according to the 2006 rules for claimants who register before the 31st of March 2007 and it is equal to the PBD according to the 2009 rules for claimants who register after the 1st of April 2007. 
Table A3: RDD estimates of discontinuities in covariates

\begin{tabular}{|c|c|c|c|c|c|c|c|c|c|}
\hline VARIABLES & $\begin{array}{c}(1) \\
\text { Log of } \\
\text { Past wage }\end{array}$ & $\begin{array}{c}(2) \\
\text { Male }\end{array}$ & $\begin{array}{c}\text { (3) } \\
\text { Education }\end{array}$ & $\begin{array}{c}\text { (4) } \\
\text { Number of } \\
\text { children }\end{array}$ & $\begin{array}{c}(5) \\
\text { Foreign } \\
\text { born }\end{array}$ & $\begin{array}{c}(6) \\
\text { Married }\end{array}$ & $\begin{array}{c}(7) \\
\text { Open-ended } \\
\text { contract }\end{array}$ & $\begin{array}{c}(8) \\
\text { Experience }\end{array}$ & $\begin{array}{c}(9) \\
\text { Replacement } \\
\text { rate }\end{array}$ \\
\hline \multicolumn{10}{|c|}{ A. All observations included around the cutoff } \\
\hline $1($ age $\geq 50)$ & $\begin{array}{l}0.0156^{* * *} \\
(0.00355)\end{array}$ & $\begin{array}{l}-0.00903 \\
(0.00666)\end{array}$ & $\begin{array}{l}0.258^{* * *} \\
(0.0574)\end{array}$ & $\begin{array}{c}-0.0309^{*} \\
(0.0167)\end{array}$ & $\begin{array}{c}-0.0280^{* * *} \\
(0.00565)\end{array}$ & $\begin{array}{c}0.00430 \\
(0.00611)\end{array}$ & $\begin{array}{l}0.0333^{* * *} \\
(0.00797)\end{array}$ & $\begin{array}{c}0.212 \\
(0.175)\end{array}$ & $\begin{array}{l}-0.000770 \\
(0.000922)\end{array}$ \\
\hline Obs. & 481,871 & 481,871 & 481,850 & 481,871 & 481,871 & 481,871 & 439,678 & 481,871 & 481,871 \\
\hline \multicolumn{10}{|c|}{ B. Excluding observations with age in $[49.9,50.1]$} \\
\hline $1($ age $\geq 50)$ & $\begin{array}{l}0.00957^{* *} \\
(0.00452)\end{array}$ & $\begin{array}{c}-0.00849 \\
(0.00859)\end{array}$ & $\begin{array}{l}0.228^{* * *} \\
(0.0687)\end{array}$ & $\begin{array}{r}-0.00680 \\
(0.0173)\end{array}$ & $\begin{array}{l}-0.00731 \\
(0.00490)\end{array}$ & $\begin{array}{c}-9.27 \mathrm{e}-06 \\
(0.00673)\end{array}$ & $\begin{array}{c}0.00597 \\
(0.00744)\end{array}$ & $\begin{array}{c}-0.339^{* *} \\
(0.168)\end{array}$ & $\begin{array}{c}-0.000493 \\
(0.00112)\end{array}$ \\
\hline Obs. & 472,209 & 472,209 & 472,188 & 472,209 & 472,209 & 472,209 & 430,855 & 472,209 & 472,209 \\
\hline \multicolumn{10}{|c|}{ C. Excluding observations with age in $[49.75,50.25]$} \\
\hline $1($ age $\geq 50)$ & $\begin{array}{c}0.00604 \\
(0.00544)\end{array}$ & $\begin{array}{l}-0.00445 \\
(0.00749)\end{array}$ & $\begin{array}{c}0.185^{* *} \\
(0.0767)\end{array}$ & $\begin{array}{l}-0.0109 \\
(0.0229)\end{array}$ & $\begin{array}{c}-0.00151 \\
(0.00606)\end{array}$ & $\begin{array}{c}-0.00523 \\
(0.00769)\end{array}$ & $\begin{array}{c}-0.00120 \\
(0.00764)\end{array}$ & $\begin{array}{l}-0.301^{*} \\
(0.176)\end{array}$ & $\begin{array}{l}-0.00123 \\
(0.00132)\end{array}$ \\
\hline Obs. & 458,337 & 458,337 & 458,316 & 458,337 & 458,337 & 458,337 & 418,204 & 458,337 & 458,337 \\
\hline \multicolumn{10}{|c|}{ D. Excluding observations with age in $[49.5,50.5]$} \\
\hline $1($ age $\geq 50)$ & $\begin{array}{l}-0.00270 \\
(0.00327)\end{array}$ & $\begin{array}{c}0.00539 \\
(0.00691)\end{array}$ & $\begin{array}{l}-0.0833 \\
(0.0537)\end{array}$ & $\begin{array}{r}-0.00718 \\
(0.0174)\end{array}$ & $\begin{array}{c}0.00414 \\
(0.00457)\end{array}$ & $\begin{array}{c}0.00409 \\
(0.00689)\end{array}$ & $\begin{array}{l}-0.00875 \\
(0.00688)\end{array}$ & $\begin{array}{c}0.00497 \\
(0.144)\end{array}$ & $\begin{array}{l}-0.00110 \\
(0.00109)\end{array}$ \\
\hline Obs. & 434,387 & 434,387 & 434,367 & 434,387 & 434,387 & 434,387 & 396,322 & 434,387 & 434,387 \\
\hline
\end{tabular}

Source: FNA-FH (Pole emploi).

Note: Standard errors in parentheses. ${ }^{* *} \mathrm{p}<0.01,{ }^{* *} \mathrm{p}<0.05,{ }^{*} \mathrm{p}<0.1$. This Table reports the estimates of a discontinuity in the distribution of covariates around the 50-year-old age cut-off, i.e coefficient $\delta$ of the following equation:

$$
X_{i}=\alpha+\delta 1\left(\text { age }_{i} \geq 50\right)+P_{0}\left(\text { age }_{i}-50\right) \times 1\left(\text { age }_{i}<50\right)+P_{1}\left(\text { age }_{i}-50\right) \times 1\left(\text { age }_{i} \geq 50\right)+\epsilon_{i}
$$

where notations have already been defined in the main text. We follow the estimation strategy of Calonico et al. (2014). The kernel used for the local polynomial estimation is triangular. 
Table A4: RDD estimates of elasticities wrt PBD (controlling for covariates)

\begin{tabular}{lccc}
\hline Age & $(1)$ & $(2)$ & $(3)$ \\
excluded & {$[49.9,50.1]$} & {$[49.75,50.25]$} & {$[49.5,50.5]$} \\
\hline \multirow{4}{*}{ Log of Reservation Wage } \\
& -0.0141 & 0.00482 & 0.0119 \\
& $(0.0138)$ & $(0.0128)$ & $(0.0103)$ \\
& \multicolumn{4}{l}{ Log of Benefit duration } \\
log PBD & $0.199^{* *}$ & $0.215^{* * *}$ & $0.161^{* *}$ \\
& $(0.0852)$ & $(0.0797)$ & $(0.0696)$ \\
\hline Obs. & 470,082 & 456,280 & 432,431 \\
\hline
\end{tabular}

Source: FNA-FH (Pole emploi).

Note: Standard errors in parentheses. ${ }^{* * *} \mathrm{p}<0.01,{ }^{* *} \mathrm{p}<0.05,{ }^{*} \mathrm{p}<0.1$. RDD estimates obtained with the corrections of Calonico et al. (2014). The kernel used for the local polynomial estimation is triangular. We control for all covariates listed in Table A3: past wage (log), gender, education (in years), number of children, foreign status, marriage status, type of past labor contract (open-ended), experience in the occupation sought and replacement rate. 
Table A5: Estimates of discontinuities in reservation wages at placebo age cutoff

\begin{tabular}{|c|c|c|c|c|c|c|c|c|c|c|}
\hline & (1) & (2) & (3) & (4) & (5) & (6) & (7) & (8) & (9) & (10) \\
\hline Placebo Age cutoff & 44 & 45 & 46 & 47 & 48 & 49 & 51 & 52 & 53 & 54 \\
\hline $1($ age $\geq$ placebo $)$ & $\begin{array}{r}-0.000210 \\
(0.00302)\end{array}$ & $\begin{array}{c}0.00464 \\
(0.00353)\end{array}$ & $\begin{array}{l}-0.00159 \\
(0.00315)\end{array}$ & $\begin{array}{c}0.00194 \\
(0.00327)\end{array}$ & $\begin{array}{c}0.00149 \\
(0.00329)\end{array}$ & $\begin{array}{c}-0.000106 \\
(0.00365)\end{array}$ & $\begin{array}{c}-0.000254 \\
(0.00396)\end{array}$ & $\begin{array}{c}0.0123^{* *} \\
(0.00591)\end{array}$ & $\begin{array}{c}-0.00552 \\
(0.00417)\end{array}$ & $\begin{array}{c}0.0147^{* *} \\
(0.00692)\end{array}$ \\
\hline Obs. & 590,095 & 564,914 & 543,235 & 521,034 & 499,192 & 478,334 & 441,441 & 427,481 & 412,624 & 392,336 \\
\hline
\end{tabular}

Source: FNA-FH (Pole emploi).

Note: Standard errors in parentheses. ${ }^{* * *} \mathrm{p}<0.01,{ }^{* *} \mathrm{p}<0.05,{ }^{*} \mathrm{p}<0.1$. This Table reports the estimates of a discontinuity in reservation wage at placebo age cutoffs, i.e coefficient $\delta$ of the following equation:

$$
\log \text { res }_{i}=\alpha+\delta 1\left(\text { age }_{i} \geq \text { placebo }\right)+P_{0}\left(\text { age }_{i}-\text { placebo }\right) \times 1\left(\text { age }_{i}<\text { placebo }\right)+P_{1}\left(\text { age }_{i}-\text { placebo }\right) \times 1\left(\text { age }_{i} \geq \text { placebo }\right)+\gamma X_{i}+\epsilon_{i}
$$

where notations have already been defined in the main text. We follow the estimation strategy of Calonico et al. (2014). The kernel used for the local polynomial estimation is triangular. We control for all covariates listed in table A3: past wage (log), gender, education (in years), number of children, foreign status, marriage status, type of past labor contract (open-ended), experience in the occupation sought and replacement rate. Consistently with our preferred specification in the main text, we exclude individuals with an age in a centered 6-month window around the placebo age. 